\title{
COMPARAÇÃO DE DELINEAMENTOS EXPERIMENTAIS NA AVALIAÇÃO DE PROGÊNIES DE MEIOS IRMÃOS DE CENOURA
}

\author{
MARCELO TAVARES \\ Engenheiro Agrônomo
}

Orientador: Prof. Dr. CYRO PAULINO DA COSTA

Tese apresentada à Escola Superior de Agricultura "Luiz de Queiroz", Universidade de São Paulo, para obtençāo do título de Doutor em Agronomia. Área de Concentração: Genética e Melhoramento de Plantas.

PIRACICABA

Estado de São Paulo - Brasil

Fevereiro - 1998 
Dados Internacionais de Catalogação na Publicacão (CIP)

DIVISÃo DE BIBLIOTECA E DOCUMENTAÇÃO - Campus "Luiz de Queiroz"/USP

Tavares, Marcelo

Comparação de delimeamentos experimentais na avaliação de progênies de meios irmãos de cenoura / Marcelo Tavares. - - Piracicaba, 1998.

$89 \mathrm{p}$.

Tese (doutorado) - - Escola Superior de Agricultura Luiz de Queiroz, 1998.

Bibliografia.

1. Cenoura 2. Delineamento de experimento 3. Melhoramento genético vegetal 4. Parâmetro genético 5. Progênie vegetal I. Titulo

CDD 635.13 


\section{COMPARAÇÃO DE DELINEAMENTOS EXPERIMENTAIS NA AVALIAÇÃO DE PROGÊNIES DE MEIOS IRMÃOS DE CENOURA}

MARCELO TAVARES

Aprovada em: 08/04/98

Comissão Julgadora:

Prof. Dr. Cyro Paulino da Costa

ESALQ/USP

Prof. Dr. Isaías Olivio Geraldi

ESALQ/USP

Prof. Dr. João Tessarioli Neto

ESALQ/USP

Prof. Dr. Norberto Silva

FCA/UNESP

Dr. Walter José Siqueira

IAC

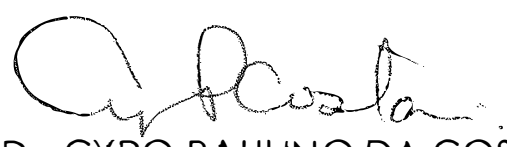

Prof. Dr. CYRO PAULINO DA COSTA

Orientador 


\section{Oferees-a}

a Deus pela razãs de micha existência

a minha esposa Girlene pelo carinho. dedieaçass e apoic:

a micha filha Givelysur. motive de isspiraças nos monentas difíceis:

aos meus irmãos Maria de Laurdes e Mareus pelo apoia:

à menória de meu pais. Ruth e Maury. que ivieiaram micha

vida na busea no coulseiments. sendo matius de men orqulho. 


\section{AGRADECIMENTOS}

Ao Instituto Agronômico de Campinas (IAC), da Secretaria de Agricultura e Abastecimento do Estado de São Paulo e à Escola Superior de Agricultura "Luiz de Queiroz", que possibilitaram a realização do curso.

Ao Conselho Nacional de Desenvolvimento Científico e Tecnológico (CNPq), pela concessão de bolsa de estudo para a realização do curso.

Ao Prof. Dr. Cyro Paulino da Costa, pelos ensinamentos, sugestões, orientação segura e, sobretudo, pela amizade.

Aos Professores Isaías Olívio Geraldi e Norberto Silva, e o Pesquisador Walter José Siqueira pela participação e sugestões que contribuíram para a melhoria deste trabalho.

Aos Pesquisadores Francisco Antônio Passos e Arlete Marchi Tavares de Melo, pelas valiosas sugestões na escrita deste trabalho, apoio, amizade e companheirismo.

Ao Dr. Hiroshi Nagai e Dr. Paulo Espíndola Trani, chefes da Seção de Hortaliças do IAC, pelo apoio e amizade.

Aos professores do Departamento de Genética da ESALQ/USP, pelos ensinamentos.

Ao prof. João Tessariolli Neto pela amizade, ensinamentos, sugestões, estímulo e ajuda durante o curso. 
Aos amigos Edson Ferreira Silva e Leonardo Novaes pelo convívio e companheirismo.

Aos colegas do curso de pós-graduação, pela convivência e companheirismo.

Aos funcionários da Seção de Hortaliças do IAC e do Departamento de Genética, da ESALQ/USP, pelo apoio e colaboração. 


\section{SUMÁRIO}

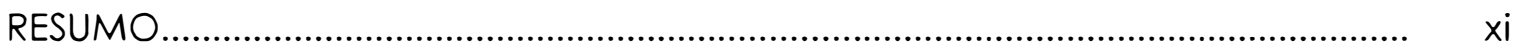

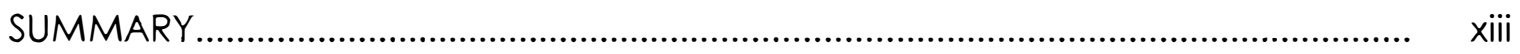

1. INTRODUÇÃ

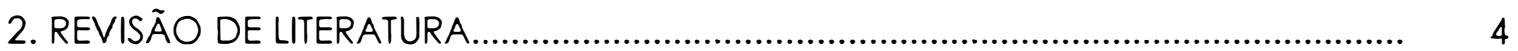

2.1. Melhoramento da cenoura...................................................................... 6

2.2. Estimativas de parâmetros genéticos no delineamento de blocos completos casualizados................................................................................ 9

2.3. Estimativas de parâmetros genéticos no delineamento de blocos completos aumentados.......................................................................... $\quad 14$

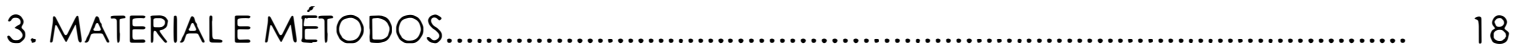

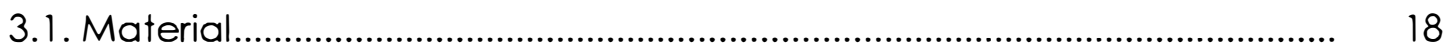

3.2. Condução dos experimentos...................................................................... 19

3.3. Delineamento experimental.................................................................. 21

3.4. Obtenção dos dados experimentais........................................................ 22

3.5. Métodos genético-estatísticos.................................................................. 23

3..6. Herdabilidades.................................................................................. 28

3.7. Coeficiente de Variação Genética e Ambiental...................................... 29

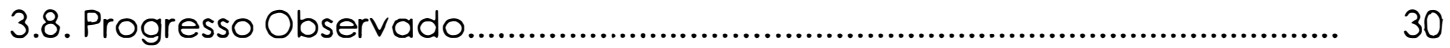

3.9. Correlação de Spearman e eficiência de seleção.................................. 30

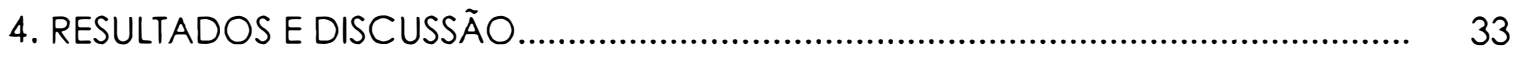

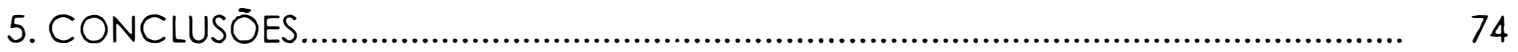

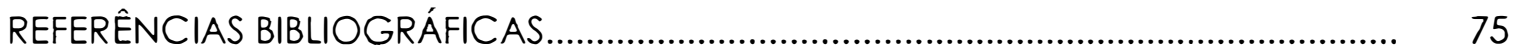

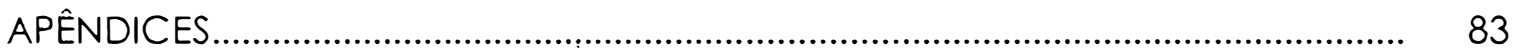




\section{LISTA DE TABELAS}

Tabela l.Esquema da análise de variância em blocos aumentados utilizando o erro intra. .24

Tabela 2. Esquema da análise de variância no delineamento de blocos completos casualizados 27

Tabela 3. Resumo das análises de variância individuais ao nível de média de parcelas para as características avaliadas

Tabela 4. Média geral para as características avaliadas.... 37

Tabela 5. Estimativas da variancia genética presente para as características avaliadas......................................................40

Tabela 6. Estimativas da variancia genética aditiva presente para as características avaliadas.......................................................4

Tabela 7. Estimativas de herdabilidade no sentido restrito para as características avaliadas......................................................4 44

Tabela 8. Coeficientes de variação genética para as características

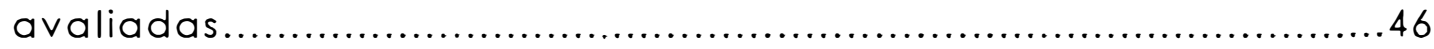

Tabela 9. Coeficientes de variação ambiental para as características

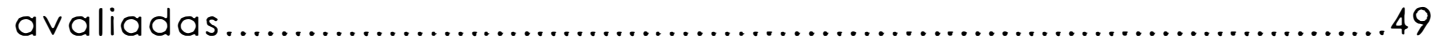


Tabela 10. Estimativas de b (relação entre $\mathrm{CVg}$ e $\mathrm{CVe}$ ) para as características avaliadas

Tabela 11. Ganhos com a seleção (GS) para as características avaliadas .54

Tabela 12. Coeficientes de correlação de Spearman entre as médias estimadas no delineamento de blocos completos casualizados e as estimadas através da estratégia de blocos aumentados para as características avaliadas

Tabela 13. Índice de coincidência (IC) entre as médias superiores do delineamento de blocos completos casualizados e blocos aumentados no local BAl para as características avaliadas.

Tabela 14. Índice de coincidência (IC) entre as médias superiores do delineamento de blocos completos casualizados e blocos aumentados no local BA2 para as características avaliadas. 63

Tabela 15. Índice de coincidência (IC) entre as médias inferiores do delineamento de blocos completos casualizados e blocos aumentados no local BAl para as características avaliadas 65

Tabela 16. Índice de coincidência (IC) entre as médias inferiores do delineamento de blocos completos casualizados e blocos aumentados no local BA2 para as características avaliadas... 
Tabela 17. Eficiência de seleção (ES) estimada em relação ao delineamento de blocos completos casualizados e blocos aumentados no local BAl para as características avaliadas. 68

Tabela 18. Eficiência de seleção (ES)estimada em relação ao delineamento de blocos completos casualizados e blocos aumentados no local BA2 para as características avaliadas.

Tabela 19. Médias de produção total de raizes das progênies e testemunhas nos três delineamentos (DBC, BAl e BA2)... 84

Tabela 20. Médias de porcentagem de florescimento prematuro das progênies e testemunhas nos três delineamentos (DBC, BAl e $B A 2)$

Tabela 21 . Médias de peso médio de raízes comerciais das progênies e testemunhas nos três delineamentos (DBC, BAl e

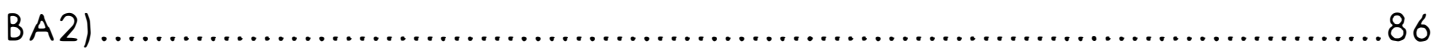

Tabela 22. Médias de porcentagem de raizes comerciais das progênies e testemunhas nos três delineamentos IDBC, BAl e $B A 2)$ .87

Tabela 23. Médias de peso médio de raízes cilíndricas comerciais das progênies e testemunhas nos três delineamentos IDBC, BAI e $B A 2)$ 
Tabela 24. Médias de porcentagem de raizes cilíndricas comerciais das progênies e testemunhas nos três delineamentos (DBC, BAI e

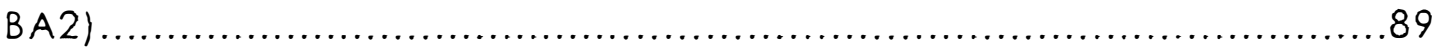




\title{
COMPARAÇÃO DE DELINEAMENTOS EXPERIMENTAIS NA AVALIAÇÃO DE PROGÊNIES DE MEIOS IRMÃOS DE CENOURA
}

\author{
Autor: Marcelo Tavares \\ Orientador: Prof. Dr. Cyro Paulino da Costa
}

\section{RESUMO}

Com o objetivo de estudar a viabilidade do uso do delineamento em blocos aumentados no programa de melhoramento de cenoura(Daucus carota L.), desenvolvido no Instituto Agronômico de Campinas (IAC), foram conduzidos dois ensaios, nos quais foram avaliadas 90 progênies de meios irmãos, originárias da cultivar Campinas - IAC 3815 e foram incluídas nos ensaios, como testemunhas, as cultivares Nantes, Campinas e Brasília. Com o propósito de comparação, cada experimento em blocos aumentados, foi considerado uma repetição, permitindo dessa forma, que os dados experimentais fossem analisados em blocos completos casualizados, considerado como delineamento padrão. A semeadura ocorreu na segunda quinzena de abril de 1996. correspondendo desta maneira ao cultivo de outono-inverno. Foram avaliadas as seguintes características: produção total de raízes, porcentagem de florescimento prematuro, peso médio de raízes comerciais, porcentagem de raízes comerciais, peso médio de raízes cilíndricas comerciais e porcentagem de raízes cilíndricas comerciais. A comparação entre os delineamentos experimentais, foi realizada com base nas estimativas de parâmetros genéticos, índice de coincidência de médias, correlação de Spearman e a eficiência de seleção segundo a metodologia proposta por Hamblin \& 
Zimmerman (1986). Verificou-se que: 0 uso do delineamento em blocos aumentados, mostrou-se viável nas fases iniciais de programas de melhoramento genético de cenoura, com intensidades de seleção mais brandas; os parâmetro genéticos estimados nos delineamentos em blocos aumentados, para maioria das características avaliadas foram de maior magnitude, devendo ser consideradas com alguma reserva; a coincidência e correlação entre as médias dos blocos aumentados com o delineamento em blocos casualizados, foram de maneira geral de magnitudes elevadas; ganho observado com a seleção, mostrou ser a seleção massai eficiente na cultura da cenoura. 


\title{
COMPARATIVE EXPERIMENTAL DESIGNS FOR EVALUATION OF HALF SIB PROGENIES OF THE CARROT
}

\author{
Author: Marcelo Tavares \\ Adviser: Prof. Dr. Cyro Paulino da Costa
}

SUMMARY

Two field assays have been carried out to evaluate the feasibility of using augmented complete block designs in the carrot (Daucus carota L.) breeding program of the Institute Agronomic Campinas (IAC). Ninety half sib progenies coming from cultivar Campinas - IAC 3815 have been tested with the cultivars Nantes, Campinas and Brasilia, included as control checks. For comparison purposes, each augmented complete block design trial (2 sites) has been considered per se as well as a replication of randomized complete block design. The genotypes were sown in the second part of April of 1996, corresponding to the autumn winter culture. The following traits have been evaluated: root overall yield, earlybloowing percentage, average weight commercial root and commercial cylindrical root and percentages commercial root and commercial cylindrical root. The comparisons between the experimental designs used have been through the magnitude of the genetical parameter estimates, index of mean coincidence, Spearman correlation and selection efficiency according to Hambin \& Zimmerman (1986) methodology. Is has been concluded that: the augmented complete block design has shoen to be feasible in the 
initial phases of the carrot breeding program under less intensive selection; the genetical parameter estimates in the augmented complete block design have given values than those of the randomized complete block design and are apparently over estimated and must be considered with reserve; the coincidence index and Spearman correlation between the augmented block and the randomized block designs means have shown high levels, in general; the massal selection is to be effective, according the observe genetic gains in the carrot population studied. 


\section{INTRODUÇÃO}

A cenoura (Daucus carota L.) atualmente cultivada originou-se de uma população taxonomicamente considerada como Daucus carota ssp. carota, sendo que existe uma hipótese de que a população básica tenha se originado a partir de uma hibridação entre Daucus carota ssp. carota e Daucus carota ssp. maximus (Banga, 1957).

A domesticação desta olerácea, realizada nos últimos 500 anos, provavelmente foi feita com base nos caracteres de raiz e resistência ao florescimento prematuro, que são caracteres de média e alta herdabilidde, respectivamente, através da seleção massal, à semelhança do que ocorreu com a cebola (Buso, 1979).

Segundo Casali (1984), o estudo da base genética, bem como a determinação de parâmetros genéticos para vários caracteres da cenoura, poderiam ter contribuido para um avanço bem maior, de pelo menos duas décadas, em relação a outras culturas de maior importância econômica.

A seleção de populações quando trata de caracteres quantitativos, deve basear-se no conhecimento de alguns parâmetros genético-estatísticos, que possibilitem um aumento da eficiência do processo seletivo para os caracteres envolvidos e um melhor controle ambiental. 
Em algumas fases dos programas de melhoramento, surge a necessidade de avaliação de várias centenas de materiais. Isto, muitas vezes, limita o tamanho da parcela experimental e o número de repetições, que acabam tendo que ser mínimos, afetando assim a eficiência da seleção (Lin \& Poushinsky, 1983).

Portanto, é necessário aplicar um método estatístico, com um máximo de informações e a um custo menor, para que a avaliação de um grande número de materiais, possa ser realizada de maneira eficiente.

Dentre os delineamentos experimentais disponiveis, quando se tem um grande número de materiais a serem avaliados, utiliza-se normalmente o delineamento em látice (Yates, 1936) mas, ainda assim, o número de parcelas experimentais pode ser grande devido a necessidade de se utilizar repetições.

Um delineamento que não utiliza repetições é o de blocos aumentados de Federer (1956), no qual as análises estatísticas são realizadas com base nas testemunhas utilizadas.

No caso do melhoramento de hortaliças, mais especificamente em cenoura, as avaliações de progênies normalmente são feitas no delineamento de blocos ao acaso, o que resulta em uma redução do número de materiais que se pode avaliar.

A escolha de um ou outro delineamento específico deve ser feita com base na magnitude das estimativas, na precisão experimental e na eficiência da seleção de genótipos superiores.

Este trabalho teve por objetivo verificar a viabilidade do uso do delineamento de blocos aumentados em relação ao de blocos ao acaso, na avaliação de progênies de meios irmãos em cenoura quanto aos seguintes parâmetros:

- Variância genética aditiva; 
- Coeficiente de herdabilidade;

- Ganho com a seleção em relação a população básica;

- Coeficiente de variação genética e ambiental;

- Eficiência da seleção sob diferentes intensidades de seleção. 


\section{REVISÃO DE LITERATURA}

A espécie Daucus carota $L$. é predominantemente alógama, sendo favorecida pela ocorrência de protandria, que se prolonga por até 2 a 3 dias (Braak \& Kho, 1958), e acentuada polinização entomófila.

A inflorescência é do tipo umbela composta, com uma haste principal tendo uma umbela central única denominada primária, que se ramifica dando origem às umbelas de segunda, terceira e quarta ordens. A umbela primária mede de 12 a $15 \mathrm{~cm}$ de diâmetro, e o tamanho decresce à medida que cresce o número de ordem (Viggiano, 1990).

As flores da umbela primária são hermafroditas, protândricas, enquanto que as demais umbelas apresentam também flores masculinas (Casali et al., 1984). O período de florescimento varia de três semanas a um mês.

A cenoura é uma planta típica de clima frio, mas o seu cultivo no mundo é feito sob condições climáticas de outono, inverno e primavera. Também já se tem materiais adaptados ao cultivo de verão.

Na evolução da cenoura, um ponto bastante importante a ser considerado é a reação ao fotoperíodo. Quando plantas adaptadas a latitudes subtropicais cresciam no verão do norte elas 
respondiam ao longo comprimento do dia através do florescimento prematuro, depreciando a valor comercial das raízes.

A tolerância ao comprimento de dia longo, deve ter sido consequência de um "roguing" prolongado das plantas que floresciam. Simultaneamente, uma dupla seleção favoreceu a necessidade de vernalização, devido as raízes serem estocadas a baixas temperaturas durante o inverno, para depois florescerem e produzirem sementes (Banga, 1976).

Inicialmente, a raiz apresentava coloração vermelha e o tipo amarela originou-se por mutação da primeira. Posteriormente, esse tipo apresentava uma alta aceitação no mercado consumidor, favorecendo assim a sua rápida disseminação para as regiōes da Ásia Menor, Arábia, Europa e Japão.

A maioria das cultivares de cenoura foram obtidas a partir das cultivares Long Orange, Late Half Long, Early Half Long e Early Scarlet Horn, por simples seleção ou por diferentes tipos de intercruzamentos (Banga, 1963).

Já o tipo de raiz mais alaranjada, que apresenta altos teores de pigmentos carotenóides, $\alpha$-caroteno e $\beta$-caroteno, que é bastante semelhante ao tipo comercializado atualmente, foi obtido por seleção massal em torno de 1600 na Holanda, a partir da cenoura amarela (Banga, 1976). 


\subsection{Melhoramento da cenoura}

O melhoramento da cenoura com a seleção de ideótipos, iniciou-se na Holanda (séculos XVII e XVIII) e na França (século XIX), sendo que a cultivar Meio Comprida de Nantes, desenvolvida na França, apresentava uma raiz de excelente qualidade e formato cilíndrico, características desejáveis no mercado consumidor /Casali et al., 1984). Posteriormente o melhoramento dessa cultura intensificou-se em outros países como Estados Unidos e Japão.

As cultivares de polinização aberta predominam no mercado. No entanto, como resultado dos estudos sobre os diferentes sistemas que controlam a macho esterilidade, já se dispõe de híbridos comerciais, principalmente no Japão (Banga, 1976).

A cenoura, do mesmo modo que a cebola, comporta-se como uma espécie bienal, ou seja, necessita de dois anos para realizar o seu ciclo vital (vegetativo e reprodutivo). O florescimento é induzido por baixas temperaturas, através do choque frio. Por sua vez, algumas populações provenientes da Ásia florescem por indução de fotoperíodo longo e crescente, apresentando um comportamento típico de espécies anuais (Casali et al., 1984).

As cenouras que eram cultivadas no Norte da Europa, exclusivamente durante o verão, floresciam prematuramente, não havendo, consequentemente, a formação completa de raízes (Banga, 1973). Houve então, uma seleção contra o caráter adaptativo florescimento, induzido pelo fotoperíodo curto. A seleção contra o florescimento prematuro no norte europeu, favoreceu o mecanismo indutivo de florescimento, exigindo assim baixas temperaturas e dias mais longos. 
A maioria das cultivares encontradas no mercado brasileiro, destinam-se ao período de outono-inverno, mas já se dispõe de diversas cultivares de primavera e verão. O mercado brasileiro tem preferência por raízes do tipo Nantes, ou seja, cilindricas e lisas (Camargo, 1984).

Desta forma, a presença de raízes cilíndricas, é uma característica de extrema importancia, que os melhoristas devem procurar busca-la nos vários materiais através de um processo de seleção.

Porém, o formato de raiz é altamente influenciado por fatores ambientais, o que torna a seleção bem mais difícil. Para essa seleção deve-se ter padrões das cultivares a serem cruzadas, além de um cuidado especial quanto a irrigação e textura do solo que podem influenciar nesta característica (Pinto, 1977).

As cultivares do tipo Nantes apesar de serem altamente produtivas e apresentarem raízes de excelente valor comercial, são altamente susceptíveis às doenças da parte aérea. Quando cultivadas fora do período outono-inverno, devem ser realizadas constantes pulverizações, onerando assim o custo de produção (Vieira \& Casali, 1984).

A cultivar Shin Kuroda foi introduzida do Japão, mostrando-se adaptada ao plantio de primavera-verão, principalmente devido a sua resistência ao calor e à queima das folhas. Porém apresenta como desvantagem, raízes cônicas, que tem um menor valor comercial (Reifschneider, 1980 e 1983). Deste material foram realizados vários ciclos de seleção, procurando como característica principal o formato cilíndrico, além da manutenção da resistência ao calor e à queima das folhas.

De populações oriundas do Rio Grande do Sul e Paraná, obtiveram-se cultivares como Tropical, Brasília e Campinas, que são 
próprias para o plantio durante o ano todo nas regiões próximas a linha do equador ou em condições de dias curtos em latitudes maiores (Costa, 1974; Camargo, 1974; Vieira et al., 1983).

A seleção recorrente baseada em famílias de meios irmãos foi utilizada no desenvolvimento das cultivares Brasília e Kuronan (Vieira et al., 1983), enquanto que a cultivar Campinas foi obtida por seleção massal (Camargo, 1984).

A seleção massal mostrou-se bastante eficiente na cenoura, principalmente pelo fato de ser a seleção de genótipos superiores realizada antes do florescimento, sendo portanto semelhante a seleção que se faz com controle dos dois sexos.

Porém muitas características de importância comercial, como o formato, são influenciadas por temperaturas mais baixas, que favorecem a produção de raízes finas e compridas (Barnes, 1936; Banga, 1955). Fato semelhante ocorre quando se tem uma irrigação menos frequente.

Desta forma, a seleção de progênies deve ser feita através de delineamentos estatísticos que possibilitem uma avaliação de um maior número de materiais e que possibilitem um melhor controle ambiental durante o processo de seleção, para que a seleção de progênies seja o mais eficiente possível. 
2.2. Estimativas de parâmetros genéticos no delineamento de blocos completos casualizados

O delineamento de blocos completos casualizados, também chamado de blocos ao acaso ou blocos casualizados foi proposto por Fisher em 1925 (Pearce, 1983). Esse delineamento faz uso de dois princípios básicos da experimentação: controle local, repetições e casualização.

Este é um dos delineamentos mais utilizados na experimentação agronômica, principalmente devido à sua simplicidade na análise e interpretação estatística dos dados. Emprega-se esse delineamento quando se suspeita que ocorra algum tipo de variação no ambiente experimental e o número de tratamentos utilizados é baixo. Os blocos podem ou não, estarem dispostos lado a lado.

Portanto, a grande maioria das estimativas de parâmetros genéticos e coeficientes de correlação em cenoura, tem sido obtidos a partir do delineamento de blocos casualizados.

Um parâmetro de grande importância para o melhoramento é a herdabilidade, pois ela expressa a proporção da variação total que é atribuída ao efeito médio dos genes. O sucesso na alteração das características de uma população com base nos valores fenotípicos, poderá ser predito através do conhecimento do grau de correspondência entre os valores fenotípico e genético, medido pela herdabilidade (Falconer, 1987).

Em programas de melhoramento, a magnitude das estimativas de herdabilidade, é crucial na definição das estratégias de seleção e também na predição de ganhos obtidos com a seleção (Fehr, 1987). 
Quando se tem caracteres que apresentam um alta herdabilidade, a seleção destes caracteres em gerações iniciais é eficiente, porém se for aplicada uma alta intensidade de seleção precoce, poderá ocorrer uma diminuição da variabilidade para importantes caracteres que apresentam baixa herdabilidade (Brim, $1973)$.

A herdabilidade não é um valor constante para um determinado caráter, pois ela depende do caráter, da população e das condições ambientais, nas quais esta estimativa foi obtida (Fehr, 1987; Falconer, 1987).

Portanto, valores estabelecidos em diferentes populações e condições ambientais, serão semelhantes somente se a estrutura da população e as condições ambientais não demonstrarem grande variação.

Este fato é demonstrado por Dowker et al. (1974), que estudando caracteres de coloração de raizes, encontrou uma variação nas estimativas de herdabilidade no sentido amplo entre locais e entre grupos de cenoura, evidenciando assim a influência da interação genótipo por ambiente.

A variação fenotípica é atribuída aos efeitos genéticos aditivos, não aditivos, e do ambiente. Estas variações podem ser resultado das combinações de todas essas variações /Robinson et al., 1951). Desta forma, torna-se importante a determinação de parâmetros como a variância aditiva, coeficientes de variação genética e herdabilidade, auxiliando assim o melhorista no momento de tomar decisões.

Della Vecchia \& Reifschneider (1983) avaliaram o nível de resistência a Alternaria dauci, sob condições noturais de infecção, em 96 progênies de meios irmãos da população de cenoura - CNPHCENI (cv. Brasília). A herdabilidade do caráter foi de 40\%, mostrando 
que a seleção em progênies de meios irmãos, pode resultar em ganho genético relativamente rápido quanto ao nível de resistência da população.

Quanto ao formato de raízes de cenoura, estudos realizados por Mazurkiewcz (1973), mostraram a relação entre a herdabilidade e a variabilidade genética de vários caracteres morfológicos no cv. Perfekcja. O autor verificou que o tamanho e o formato de raízes, submetidos a longos períodos de seleção, apresentaram baixa variabilidade genética (8-14\%) com valores de herdabilidade entre 30 e $50 \%$. Esses resultados são próximos aos obtidos por McCollum (1971), indicando assim uma alta influência do ambiente na expressão do caráter em diferentes condições.

Vieira (1988) encontrou valores de herdabilidade para o indice de formato de raízes, variando de $34 \%$ a $60 \%$ em populações de cenoura, os quais foram semelhantes aos valores encontrados na literatura.

Com relação à produção, Brar \& Sukhija (1981), encontraram $85,7 \%$ de herdabilidade e $34,3 \%$ de coeficiente de variação genotípica, que confirmaram os resultados obtidos no ano anterior (Brar \& Sukhija, 1980). Della Vechia \& Pessoa (1984) estudando as cultivares Kuronan e Brasilia encontraram para a porcentagem de raizes comerciais, estimativas de herdabilidade de $52.21 \%$ e $64.41 \%$ para as cultivares Kuronan e Brasília, respectivamente.

Ao determinarem a variabilidade genética existente em 11 cultivares de cenoura procedentes de diferentes regiões da índia, Korla et al. (1980) verificaram que o caráter produção de raízes apresentou $64,3 \%$ de herdabilidade e $20,2 \%$ de coeficiente de variação genotípica. O ganho genético para o caráter peso de raiz foi de $18,27 \%$. 
As estimativas de herdabilidade encontradas por Vieira (1988) para produção apresentaram uma variação entre as populações estudas, sendo os limites de $59,0 \%$ a $80 \%$. Já para a característica peso de raízes comerciais, ocorreu uma variação semelhante, sendo a menor de 53,0 e maior de $78,0 \%$.

Quanto a vigor de folhagem, estudos realizados por Brar \& Sukhija (1980) mostraram que esse caráter apresenta altos valores de herdabilidade chegando a $90 \%$. Esse resultado evidencia a presença de efeitos aditivos relacionados à variabilidade genotípica, cujo valor para o caráter foi de $34,8 \%$. Já, para comprimento e diâmetro da raiz e número de folhas o ganho genético foi menor, indicando que esses caracteres são controlados principalmente por genes de efeito não-aditivo. Portanto, a seleção com base no fenótipo dos caracteres peso e comprimento da folhagem e peso da raiz resultará também na escolha de genótipos superiores, considerando os valores de herdabilidade e ganho genético esperado.

O florescimento prematuro, segundo Vieira \& Casali (1984), é uma característica que tem sido muito pouco estudada pelos melhoristas, quanto à estimação de parâmetros genéticos. Entretanto, Della Vecchia \& Pessoa (1984) obtiveram para esse caráter estimativas de herdabilidde, cujos valores variaram de $94,65 \%$ a $77,94 \%$ em diferentes cultivares.

Em estudo realizado por Siqueira (1989), verificou-se que as estimativas de herdabilidade para progênies de meios irmãos de cenoura foram de $90,76 \%, 80,84 \%, 68,47 \%$ e $66,74 \%$ para porcentagem de florescimento, porcentagem de raízes cilindricas comerciais, peso médio de raízes cilíndricas comerciais e produção total, respectivamente. Os coeficientes de variação genética foram de $32,47 \%$ para porcentagem de florescimento e de $12,60 \%$ para 
porcentagem de raízes cilíndricas comerciais, sendo que a produção total e o peso médio de raízes cilíndricas comerciais estiveram próximos de 7\%. Entretanto, Vieira (1988), encontrou valores bem maiores de coeficiente de variação genética $(30,9 \%$ a $21,3 \%)$ para a produção tołal de raízes. Já o peso de raízes comerciais, apresentou estimativas que variaram de $23,7 \%$ a $41 \%$.

O ganho com a seleção obtido por Siqueira (1989) foi alto apenas para a porcentagem de florescimento prematuro $(30,73 \%)$ e menor que $11 \%$ para as outras características citadas. O valor de b, que é a relação entre o coeficiente de variação genética e o ambiental, mostrou-se baixo, variando de 0,71 para a produção total até 1,57 para a porcentagem de florescimento prematuro, estando estes resultados semelhantes aos obtidos por Vieira (1988), onde os valores de b estiveram próximos de um. Os coeficientes de variação ambiental para as demais características avaliadas foram menores que $13 \%$, indicando uma boa precisão experimental, exceto para porcentagem de florescimento prematuro que foi de $20,72 \%$.

A comparação dos resultados encontrados na literatura, deve ser feita com uma certa cautela, pois os parâmetros foram obtidos ao nivel de médias, sendo portando altamente afetados pelo número de repetições. O ideal é que os parâmetros fossem obtidos ao nível de indivíduo para que pudessem ser melhor comparados. 
2.3. Estimativas de parâmetros genéticos no delineamento de blocos aumentados

No delineamento de blocos aumentados, os tratamentos repetidos são designados de comuns, e os adicionais de regulares. Como não há necessidade de se utilizar repetições, é possível avaliar um número maior de tratamentos, em comparação com os delineamentos convencionais, apesar de se ter um aumento no erro padrão das médias.

Este delineamento foi inicialmente proposto por Federer (1956), para que pudesse ser feita a seleção de novos híbridos dentro de um programa de melhoramento de cana-de-açúcar no Hawai, devido ao grande número de clones que deveriam ser avaliados.

No delineamento de blocos aumentados deve-se primeiro determinar o número de testemunhas que deverá ser utilizado (no mínimo duas) e posteriormente o tamanho dos blocos, onde estarão presentes as testemunhas e as progênies que irão compor cada bloco. Desta forma, procede-se o sorteio das progênies a serem avaliadas e depois o sorteio das testemunhas dentro de cada bloco.

Neste tipo de delineamento, há um controle local generalizado em blocos, sendo que estes não apresentam um tamanho específico, podendo variar tanto dentro como entre experimento.

Federer (1956), propôs inicialmente a análise de variância com controle local em gradiente, incluindo tanto blocos completos quanto incompletos. Posteriormente (Federer et al., 1975), apresentaram uma análise para casos com controle local em mais de uma direção. 
Lin \& Poushinsky (1983), propuseram um delineamento aumentado modificado para melhorar a eficiência da avaliação de linhagens em fases iniciais de um programa de melhoramento. Dessa forma, os controles foram dispostos de maneira sistemática em linhas e colunas e não aleatoriamente. Schaalje et al. (1987), verificaram que esse delineamento modificado em um programa de melhoramento de batata proporcionou uma redução na variância residual, afetando a classificação dos materiais.

O tamanho do bloco não é rígido, pois os tratamentos regulares podem ter diferentes números dentro dos blocos, dando uma maior flexibilidade para o planejamento e a condução dos experimentos. Esta flexibilidade no número de tratamentos regulares, faz com que a perda de alguns desses tratamentos não comprometa a análise dos dados (Federer, 1961a; Federer, 1961b).

Quando houver necessidade de uma análise conjunta, Nogueira (1976) mostrou que a média dos tratamentos seriam ajustadas não só pelo bloco de cada local, mas também para locais, e desenvolveu os estimadores quando tratamentos e ambientes são ortogonais entre si.

Por sua vez, Silva (1987) determinou os estimadores para os efeitos dos parâmetros do modelo, quando for necessário uma análise de covariância em blocos aumentados.

Segundo Bearzoti (1994), é melhor repetir um ou mais tratamentos comuns dentro dos blocos, do que aumentar o número de blocos, que permite obter uma melhoria da precisão experimental.

Ainda esse autor, avaliando clones de batata nas fases iniciais de um programa de melhoramento, utilizando o delineamento de blocos aumentados, obteve estimativas do coeficiente de variação entre $5,73 \%$ para a matéria seca dos tubérculos e $26,67 \%$ 
para peso médio de tubérculos comerciais. As estimativas de herdabilidade variaram de $72,67 \%$ para produção total a $1,92 \%$ para porcentagem de tubérculos graúdos.

Momenté (1994), usou o delineamento de blocos aumentados para determinar a variabilidade existente em populações de batata, obtidas de diversas maneiras. A partir da análise de variancia intra-blocos, foram retiradas as variancias das diferenças entre as médias ajustadas dos tratamentos regulares e calculado o quadrado médio do resíduo efetivo. Este foi usado para compor uma nova análise de variância, e assim foi possível comparar os tratamentos regulares testados em diferentes blocos. Os valores de herdabilidade encontrados, foram maiores do que os encontrados na literatura para batata.

Souza (1997) comparou diferentes alternativas na avaliação de progênies em programas de melhoramento genético do feijoeiro e de eucalipto. Constatou que o delineamento de blocos aumentados mostrou-se viável nas fases iniciais de programas de melhoramento para a seleção de progênies dessas culturas. Além disso, demonstrou que esse delineamento não é indicado nestas culturas para estimação de parâmetros genéticos e fenotípicos, pois os mesmos mostraram uma baixa precisão, quando calculou-se o erro dos parâmetros.

Uma das principais limitações para o uso de delineamentos aumentados, devia-se à necessidade de uso de fórmulas complexas de cálculo (Nogueira \& Pimentel Gomes, 1978a; Nogueira \& Pimentel Gomes, 1978b) e à ausência de programas de computador que fizessem esta análise.

Desta forma Scott \& Miliken (1993), apresentaram uma rotina para análise de dados obtidos através do delineamento em blocos completos aumentados, para o programa SAS. 
O uso do delineamento de blocos aumentados no melhoramento de cenoura ainda é reduzido como mostra a literatura, pois não foi encontrada nenhuma citação tratando da obtenção de estimativas de parâmetros genéticos ou avaliação de progênies para a cultura. 


\section{MATERIAL E MÉTODOS}

\subsection{Material}

O material utilizado no presente trabalho foi constituído de 90 progênies de meios irmãos, originárias da cultivar Campinas IAC 3815. Essa cultivar foi desenvolvida na Seção de Hortaliças Diversas, do Instituto Agronômico de Campinas, e lançada oficialmente em 1965, pelo Dr. Leocádio de Souza Camargo (Camargo, 1984).

A obtenção da cultivar Campinas será mostrada a seguir, de forma bastante suscinta.

Em 1946, um material local mantido pelos agricultores do município de Ibiti, SP, foi introduzido na Seção de Hortaliças Diversas (acesso no 493), sendo submetida a vários ciclos de seleção massal, dando origem em 1955 a cultivar "Meio Comprida."

A cultivar "Meio Comprida", foi cruzada manualmente com a cultivar Nacional, que era procedente da empresa de sementes Merlo Braz Ltda, situada em Jaguarão, RS. Nas descendências desse cruzamento foram realizados, novamente, vários ciclos de seleção massal.

Em 1959 obteve-se a cultivar "Meio Comprida Precoce," que apresentava resistência à queima das folhas causada por 
Alternaria dauci, que foi cruzada com a cultivar "Paraná", mantida por agricultores da região de Londrina, PR. Depois de vários ciclos de seleção massal obteve-se, em 1965, a cultivar "Campinas".

Em todas as fases de obtenção da cultivar "Campinas, a seleção foi realizada no Núcleo Experimental de Campinas (IAC), nas condições de cultivo de outono-inverno. As principais características selecionadas foram para produção, formato cilíndrico, resistência a queima das folhas (Alternaria dauci) e florescimento prematuro.

Apesar dos vários ciclos de seleção massal, a sensibilidade ao frio e fotoperíodo, no que diz respeito ao florescimento prematuro, e à ausência de padrão definido de formato de raízes fizeram com que a cultivar não tivesse êxito junto aos agricultores. A partir do material original (cultivar Campinas) lançado, foram realizados novos ciclos de seleção para que esses problemas pudessem ser diminuídos obtendo-se assim progênies melhoradas.

Além das 90 progênies de meios irmãos avaliadas, foram incluídas nos ensaios, as cultivares Brasília $\left(T_{1}\right)$, Campinas $\left(T_{2}\right)$ (população básica) e Nantes ( $T_{3}$ ), que foram utilizadas como testemunhas, possibilitando assim a análise em blocos aumentados.

A cultivar Campinas (população básica) também serviu como referência, para o cálculo do ganho genético dos vários ciclos de seleção e verificar a eficiência da seleção.

\subsection{Condução do Experimento}

As 90 progênies de meios irmãos, bem como as testemunhas foram avaliadas em 2 ensaios, e em ambos adotou-se o delinamento de blocos aumentados. O local dos ensaios foi o Núcelo 
Experimental de Campinas (NEC), do Instituto Agronômico de Campinas (IAC).

A semeadura dos dois ensaios foi realizada na segunda quinzena de abril de 1996, correspondendo ao cultivo de outonoinverno. Os ensaios foram instalados em dois locais distintos do Centro Experimental, distando cerca de cinco quilômetros. Um deles foi instalado em área experimental da Seção de Hortaliças, conhecida como Ponte Seca (BAl) onde o solo mostrou argiloarenoso e o outro em área próxima à Seção de Genética (BA2) com o solo com características que o classificava como argiloso.

Os canteiros foram previamente preparados, tendo a saturação por bases trocáveis elevada a $80 \%$. Como adubação orgânica utilizou-se esterco de curral bem curtido na quantidade de 30 toneladas por hectare. A adubação mineral foi realizada cerca de 10 dias antes da semeadura nas seguintes quantidades: $20 \mathrm{~kg} / \mathrm{ha}$ de $\mathrm{N}, 200 \mathrm{~kg} / \mathrm{ha}$ de $\mathrm{P}_{2} \mathrm{Os}$ e $110 \mathrm{~kg} / \mathrm{ha}$ de $\mathrm{K}_{2} \mathrm{O}$. Foi aplicado, juntamente com N,P e K, $1,5 \mathrm{~kg} / \mathrm{ha}$ de B. Em cobertura foram aplicados $80 \mathrm{~kg} / \mathrm{ha}$ de $\mathrm{N}$ e $45 \mathrm{~kg} / \mathrm{ha}$ de $\mathrm{K}_{2} \mathrm{O}$, que foram parcelados em três aplicações aos 15,30 e 50 dias após a emergência.

Foi utilizada uma densidade de semeadura em torno de uma grama de sementes por metro linear de sulcos. Os canteiros foram preparados com um metro de largura, e os sulcos transversais ao canteiro foram espaçados em $25 \mathrm{~cm}$.

Cada parcela foi constituída de seis linhas e as quatro linhas centrais totalizando um metro quadrado, foram consideradas como parcela útil. A distância entre parcelas foi de $30 \mathrm{~cm}$, e os canteiros foram espaçados de $50 \mathrm{~cm}$.

Os desbastes foram realizados em duas etapas, aos 30 e 45 dias após a semeadura. As parcelas ficaram com uma densidade 
de plantas em torno de 60 plantas, ou seja em torno de 420.000 plantas por hectare.

Os tratos culturais tais como irrigação, pulverizações preventivas e capinas realizados durante 0 desenvolvimento das plantas, foram os normalmente indicados para a cultura da cenoura.

As colheitas foram realizadas no período de 102 a 112 dias após a semeadura, nos dois ensaios.

\subsection{Delineamento Experimental}

Para os dois ensaios, o delineamento utilizado foi o de blocos completos aumentados.

Para que se pudesse ter uma idéia da eficiência do uso desse delineamento em relação a um delineamento padrão, os dados provenientes dos dois ensaios foram analisados em blocos casualizados, sem ajuste das médias, sendo que cada ensaio foi considerado como um bloco. Desta forma procedemos a análise em blocos casualizados, considerado padrão, com duas repetições.

Por sua vez, as análises de blocos aumentados foram realizadas com base nas médias ajustadas obtidas através da análise de variância. De posse dos parâmetros estimados no delineamento de blocos aumentados e em blocos casualizados foi efetuada a comparação da magnitude dessas estimativas.

As análises genético-estatísticas foram realizadas segundo os seguintes programas: SAS (1985) e MAPGEN'.

IPrograma desenvolvido pelo Prof. Dr. Daniel Furtado Ferreira do Departamento de Ciências Exatas da Universidade Federal de Lavras (UFLA), Lavras - MG (não publicado). 


\subsection{Obtenção dos dados experimentais}

As avaliações ao nível de parcelas, foram realizadas principalmente com base nos caracteres de raiz, que é o produto comercial da cenoura.

1. Produção Total de raízes por parcela (PTR): é o peso total das raizes de cada parcela $\left(1 \mathrm{~m}^{2}\right)$, expresso em gramas.

2.Florescimento prematuro (\%FLOR): é a porcentagem de plantas que emitiram a haste floral prematuramente, durante o seu ciclo vegetativo, em relação ao número total de raízes. Esta característica foi anotada um pouco antes da colheita;

3. Porcentagem de raízes comerciais (\%RCo): é a porcentagem de raizes que apresentaram valor comercial em relação ao número total de raizes. O critério de classificação de raizes em comerciais, baseou-se no comprimento maior que $10 \mathrm{~cm} \mathrm{e}$ ausência de defeitos, como rachaduras e bifurcações. Também estiveram incluidas raízes de formato cônico e cilíndrico;

4. Peso médio de raízes comerciais (PMRCo): refere-se a razão entre o peso total de raízes comerciais por parcela e o número de plantas que apresentaram raizes comerciais.

5. Porcentagem de raízes cilindricas comerciais (\%RCiCo): é a porcentagem de raizes que apresentam um tamanho comercial maiores do que $10 \mathrm{~cm}$, formato cilindrico e ausência de defeitos, em relação ao número total de raízes; 
6. Peso médio de raízes cilindricas comerciais (PMRCiCo): foi obtido através da razão entre o peso total de raízes cilíndricas comerciais e o número de raízes cilíndricas comerciais;

Os dados expressos em porcentagem não foram transformados para arc sen (\%) $1 / 2$, para que se pudesse estimar melhor o coeficiente de variação ambiental e o comportamento dos dois delineamentos experimentais.

3.5. Métodos genético-estatísticos

O modelo matemático para o delineamento de blocos aumentados é o seguinte:

$Y_{i j}=\mu+t_{i^{\prime}}+t_{(j) i}+b_{j}+e_{i j}$

onde:

$Y_{\mathrm{ij}}$ : valor observado na parcela do bloco j que recebeu ou o tratamento comum i' ou o tratamento regular i dentro do bloco j;

$\mu$ : efeito fixo da média geral;

$\mathrm{t}_{\mathrm{i}^{\prime}}$ : efeito do tratamento comum i', que, em geral, é tido como fixo;

$t_{(j) i}$ : efeito do tratamento regular i dentro do bloco j, que, em geral, é tido como aleatório em programas de melhoramento; 
$b_{\mathrm{j}}$ : efeito aleatório do bloco j;

$\mathrm{e}_{\mathrm{ij}}$ : efeito aleatório do erro experimental associado à parcela do bloco j que recebeu ou o tratamento comum i' ou o tratamento regular i dentro do bloco j, admitindo-se que os erros são independentes e normalmente distribuídos, com média zero e variância $\sigma^{2}$.

O delineamento assumiu $k_{j}$ número total de parcelas por bloco e p número de parcelas em cada bloco que contém os tratamentos comuns.

O esquema da análise de variância para o delineamento de blocos aumentados é apresentado na Tabela 1.

Tabela 1. Esquema da análise de variância em blocos aumentados utilizando o erro intra.

\begin{tabular}{llll}
\hline Causas de Variação & G.L. & QM & Teste F \\
\hline Bloco & $(b-1)$ & $-\cdots--$ & \\
Tratamento ajustado & $(p+t-1)$ & $Q M_{2}$ & $Q M_{2} / Q M_{1}$ \\
Erro Intra & $(t-1)(b-1)$ & $Q M_{1}$ & \\
\hline Total & $N-1$ & & \\
\hline
\end{tabular}

b: número de blocos;

t: número de testemunhas (tratamentos comuns); 
p: número de progênies (tratamentos regulares);

$\mathrm{N}$ : número total de parcelas

O erro intra-blocos, obtido na referida análise, só permite comparações entre tratamentos regulares testados no mesmo bloco. A comparação entre progênies situadas em diferentes blocos deve ser feita com um erro $\sigma_{e^{\prime}}^{2}$, utilizando-se as médias ajustadas dos tratamentos regulares. Entretanto, para evitar 0 uso de dois erros diferentes, procurou-se estimar o erro efetivo médio $\sigma_{e f}^{2}$.

A partir da análise intra-blocos, estimou-se as variâncias entre tratamentos regulares do mesmo bloco e de blocos diferentes, e com estes valores, calculou-se a variância do erro efetivo médio. Ferreira citado por Barbosa (1996) desenvolveu um testador o qual foi denominado erro efetivo, que é obtido pela seguinte expressão.

$$
\mathrm{QME}_{\mathrm{e}}=\left(1+\frac{1}{r+t-1}+\frac{r}{t(r+t-1)}+\frac{r \sum_{k=1}^{b} n_{k}^{2}}{t^{2}(r+t-1)}-\frac{2 \sum_{k=1}^{b} n_{k}^{2}}{\operatorname{tn}(r+t-1)}+\frac{b \sum_{k=1}^{b} n_{k}^{2}}{n^{2}(n+t-1)}\right) \text { QME† }
$$

onde:

QME $E_{e}$ : quadrado médio do erro efetivo;

r: número de tratamentos regulares;

t: número de tratamentos comuns; 
b: número de blocos;

$n_{k}$ : número de tratamentos (regulares + comuns) no blocos k;

n: número total de parcelas $\left(n=\sum_{k=1}^{b} n_{k}\right)$;

QMEł: quadrado médio do erro da análise intrablocos.

Posteriormente, calculou-se a variância entre as médias ajustadas, obtidas a partir da análise utilizando o erro intra. Desta variância, constituiu-se o quadrado médio de tratamento, sendo que, nesta análise utilizou-se o erro efetivo. Os componentes da variância foram estimados como se fossem um delineamento inteiramente casualizado com uma repetição.

A análise de variância realizada segundo o delineamento de blocos casualizados, considerando cada local como sendo um bloco (repetição), segue o esquema da tabela 2 e considera o seguinte modelo estatístico:

$Y_{i j}=\mu+t_{i}+b_{j}+e_{i j}$

onde

$Y_{i j}$ : observação do i-ésimo genótipo de j-ésimo bloco;

$\mu$ : média geral das progênies; 
$t_{i}$ : efeito do i-ésimo tratamento (progênie);

$b_{j}$ : efeito do j-ésimo bloco;

$e_{i j}$ : efeito do erro experimental

Tabela 2. Esquema da análise de variância no delineamento de blocos completos casualizados.

\begin{tabular}{lllll}
\hline F.V. & G.L. & $Q M$ & Teste F & $E(Q M)$ \\
\hline Blocos & $r-1$ & $Q M_{3}$ & $Q M_{3} / Q M_{5}$ & \\
Tratamentos & $i-1$ & $Q M_{4}$ & $Q M_{4} / Q M_{5}$ & $\sigma_{e}^{2}+r \sigma_{g}^{2}$ \\
Erro & $(j-1)(i-1)$ & $Q M_{5}$ & & $\sigma_{e}^{2}$ \\
\hline
\end{tabular}

$\sigma_{g}^{2}$ : estimativa da variância genética entre as progênies com base na análise de variância;

$\sigma_{e}^{2}$ : corresponde a variância de observação, ou seja o erro experimental;

r: número de repetições (blocos);

i: número de tratamento (progênies);

A variância genética para o delineamento de blocos casualizados foi obtida através da seguinte expressão:

$\sigma_{g}^{2}=\left(Q M_{4} / Q M_{5}\right) / r$ 
$\sigma_{e}^{2}=Q M 5$

No caso do delineamento de blocos aumentados as variâncias genéticas foram obtidas da mesma maneira, considerando apenas o valor derigual a 1.

\subsection{Herdabilidades}

De acordo com Cockerham (1963) e Falconer (1987) a variância genética entre progênies de meios irmãos é igual a $1 / 4$ da variância aditiva do caráter considerado. Portanto a estimativa da variância genética aditiva foi obtida por:

$$
\sigma_{A}^{2}=4 . \sigma_{G}^{2}
$$

Para cada caraterística foi determinada o coeficiente médio de herdabilidade, para as progênies de meios irmãos, conforme a seguinte expressão:

$$
h^{2}=\frac{\sigma_{G}^{2}}{\sigma_{\bar{F}}^{2}}
$$

onde:

$h^{2}$ : herdabilidade do caráter considerado, considerando a média da progênie; 
$\sigma_{G}^{2}$ : variância genotípica entre médias de progênies de meios irmãos;

$\sigma_{F}^{2}$ : variância fenotípica entre progênies de meios irmãos, com base na média entre parcelas;

3.7. Coeficientes de Variação Genética e Ambiental

Para cada característica foi determinado o coeficiente de variação genética $(C \vee g)$, o coeficiente de variação experimental $(C V e)$ e a relação (b) entre CVg e Cve.

$$
b=C V g / C V e
$$

O coeficiente de variação genética foi estimado através da expressão:

$C V g=\left(\frac{\hat{\sigma}_{g}}{\bar{X}}\right) 100$

O coeficiente de variação experimental, foi obtido pela seguinte expressão:

$C V e=\left(\frac{\hat{\sigma}_{e}}{\bar{X}}\right) 100$

onde: 
$\bar{X}$ : média do caráter;

$\hat{\sigma}_{g}:$ desvio padrão genotípico;

$\hat{\sigma}_{\text {e }}$ :desvio padrão do erro experimental.

\subsection{Progresso Observado}

O progresso observado foi calculado pela relação entre as progênies de meios irmãos obtidas através destes vários anos de seleção e a população original da cultivar Campinas através da seguinte expressão:

$G s=\left[\frac{\left(\bar{X}_{\text {progenies }}-\bar{X}_{\text {Compinas }}\right)}{\bar{X}_{\text {Compinas }}}\right] 100$

3.9. Correlação de Spearman e Eficiência de Seleção

Com a intenção de verificar a maneira pela qual a análise de cada delineamento - em blocos casualizados e blocos aumentados - pode interferir na ordem das médias, procurou-se calcular a correlação de Spearman (rs) (Steel \& Torrie, 1980). A correlação foi calculada entre as médias originais considerando o delineamento de blocos casualizados como padrão e as médias 
ajustadas, obtidas pela análise de blocos aumentados, através da seguinte fórmula:

$r_{s}=1-\frac{\left(6 \sum_{i} d_{i}^{2}\right)}{(n-1) n(n+1)}$

onde,

$d_{i}$ : diferença entre o i-ézimo par;

$\mathrm{n}$ : número de pares.

Além da comparação dos métodos no tocante as estimativas dos parâmetros genéticos e do coeficiente de correlação de Spearman verificou-se o índice de coincidência entre as médias dos delineamentos comparados, considerando-se as progênies superiores e inferiores, em diferentes intensidades de seleção. O índice de coincidência será dado pela seguinte expressão:

$$
I C=\left(\frac{E}{F}\right) \cdot 100
$$

onde:

E: número de progênies com classificação de médias coincidentes entre os delineamentos, nas intensidades de seleção utilizadas;

F: número total de progênies consideradas. 
Como mais um critério para comparação dos delineamentos, aplicou-se o método proposto por Hamblin \& Zimmermann (1986), que diz respeito a estimativa da eficiência de seleção em cada ensaio. Através deste método, obtem-se a proporção de progênies que o delineamento de blocos aumentados consegue identificar e que são coincidentes com as progênies selecionadas no tipo padrão. Os valores são calculados pela expressão:

$$
E S(\%)=\left(\frac{A-D}{B-D}\right) \cdot 100
$$

onde:

A : número de progênies selecionadas que foram coincidentes tanto no delineamento considerado como no padrão;

8: número de progênies selecionadas que varia de acordo com a intensidade de seleção utilizada;

D: número esperado de progênies por simples coincidência, unicamente devido ao acaso, que é estimado através do produto da intensidade de seleção pelo número de progênies selecionadas. 


\section{RESULTADOS E DISCUSSÃO}

Nos programas de melhoramento genético, a avaliação de progênies está sempre limitada quando envolve um grande número de materiais, de forma que se possa explorar uma maior variabilidade genética da população. Como alternativa para solução desse problema, devem ser utilizados delineamentos e métodos estatísticos que possibilitem a otimização dos recursos financeiros e humanos. Dentro deste contexto, o delineamento de blocos aumentados, se encaixa perfeitamente nesta situação desejável, sendo necessário somente, verificar a sua eficiência seletiva e a viabilidade do seu uso na avaliação de progênies de meios irmãos de cenoura.

A tabela 3 mostra o resumo das análises de variância para cada delineamento. As estimativas dos quadrados médios do erro variaram bastante nos delineamentos estudados, mas de um modo geral apresentaram maior valor para o delineamento de blocos completos casualizados. Isto está associado a grande discrepância entre os dois locais, já que cada um foi considerado como uma repetição (bloco).

Este delineamento apresentou, também maior magnitude nas estimativas do quadrado médio de tratamento para todas as características estudadas, quando comparado com o delineamento em blocos aumentados no local BA2. Por outro lado, no ensaio do 
Tabela 3. Resumo das análises de variância individuais ao nível de média de parcelas para as características avaliadas.

\begin{tabular}{|c|c|c|c|c|c|c|}
\hline \multirow[b]{2}{*}{$\begin{array}{l}\text { Caracte- } \\
\text { risticas }\end{array}$} & \multicolumn{3}{|c|}{$\begin{array}{c}\text { QMTratamentos } \\
\text { (GL) }\end{array}$} & \multicolumn{3}{|c|}{$\begin{array}{l}\text { QMErro } \\
\text { (GL) }\end{array}$} \\
\hline & $\begin{array}{l}\mathrm{DBC} \\
(92)\end{array}$ & $\begin{array}{l}\mathrm{BA} 1 \\
(92)\end{array}$ & $\begin{array}{l}\mathrm{BA2} \\
(92) \\
\end{array}$ & $\begin{array}{l}\mathrm{DBC} \\
(92)\end{array}$ & $\begin{array}{l}\mathrm{BA} 1 \\
(8)\end{array}$ & $\begin{array}{c}\mathrm{BA2} \\
(8)\end{array}$ \\
\hline PTR & $2446669,46^{* *}$ & 2221461,98 n.s. & $1647579,58^{*}$ & 1085948,98 & 1040597.73 & 324257,94 \\
\hline$\%$ FLOR & $731,27^{*}$ & $364,58 *$ & $377.72 *$ & 22,10 & 93,19 & 90,6810 \\
\hline PMRCO & 567,87 n.s. & 671.63 n.s. & $435,22 * *$ & 469,69 & 232,84 & 77,84 \\
\hline$\%$ RCo & 5001,33 n.s. & 346,14 n.s. & $329,00 * *$ & 5050,73 & 181,36 & 33,37 \\
\hline PMRCiCo & 1237.76 n.s. & $1303,29 * *$ & $1149.13^{* *}$ & 1227,58 & 143,86 & 55,83 \\
\hline$\%$ RCiCo & 210,04 n.s. & $232,23^{* *}$ & $219,02^{* *}$ & 236,61 & 46,59 & 34,13 \\
\hline
\end{tabular}

PTR: produçāo total de raízes

\%FLOR: porcentagem de florescimento prematuro

PMRCo: peso médio de raizes comerciais
\%RCo: porcentagem de raizes comerciais

PMRCiCo: peso médio de raizes cilindricas comerciais

\%RCiCo: porcentagem de raizes cilindricas comerciais

BA1: Delineamento em blocos aumentados no local ponte seca;

BA2: Delineamento em blocos aumentados no local genética;

DBC: Delineamento em blocos completos casualizados.

* significativo ao nível de $5 \%$

** significativo ao nível de $1 \%$

n.s. não significativo 
local BAI, as estimativas do quadrado médio de tratamento foram superiores apenas para as características,

produção total de raízes, peso médio de raízes cilíndricas comerciais e porcentagem de raizes comerciais.

Esta variabilidade fenotípica é devido não só a fatores genéticos, mas também a fatores de ambiente e da interação entre os genótipos e o ambiente. Portanto, uma seleção com base em progênies que apresentem uma maior porcentagem de raízes cilindricas, deve ser realizada de maneira criteriosa, já que esta característica é altamente influenciada pela condições de cultivo. Deve-se então, utilizar um maior número de locais na avaliação destas progênies e procurar obter um melhor controle das condições experimentais.

Houve concordância entre as significâncias no teste de $F$ apenas para a porcentagem de florescimento prematuro, ao nível de significância de $5 \%$ em todos os delineamentos estudados. Esta concordância ocorreu devido as condições de micro ambiente afetarem muito pouco esta característica, tais como condições de solo, irrigação e adubação. Já as condições climáticas foram possivelmente semelhantes, atuando de maneira mais uniforme nos dois locais, e consequentemente nas progênies avaliadas.

Nas características em que não foi possível detectar diferenças significativas, associou-se o fato, aos maiores valores estimados do coeficiente de variação ambiental (Tabela 9). Deste modo, fica evidente a importancia do controle das possiveis causas de variação para que se possa discriminar os materiais avaliados e aumentar a chance de sucesso durante o processo de seleção, principalmente com características como a produção e o formato das raízes. 
O número de graus de liberdade do quadrado médio do erro (Tabela 3) foi menor no delineamento de blocos aumentados, devido principalmente, ao pequeno número de testemunhas utilizado. Uma maneira de diminuir esse "incoveniente" é através do uso de um número maior de tratamentos comuns ou testemunhas e blocos.

As estimativas dos quadrados médios do erro (QMErro), apresentaram diferenças nos delineamentos estudados. Os valores foram menores no local BA2, exceto para a porcentagem de florescimento prematuro (Tabela 3 ). Esses resultados mostram que apesar das médias terem sido menores para a maioria das características avaliadas no local BA2 (Tabela 4), as testemunhas se comportaram de maneira pouco variável, mostrando que neste local as condições de solo, apesar de adversas, foram mais uniformes. Como decorrencia deste fato, as maiores diferenças ocorreram principalmente para as características relacionadas ao formato da raiz, que são altamente influenciadas pelas condições de solo, como demonstrou Barnes (1936) e Banga (1955).

A tendência de menores valores do quadrado médio do erro no delineamento de blocos aumentados, deve-se ao fato de que o erro foi estimado a partir das testemunhas, e o comportamento destas em relação às progênies foi bem marcante e uniforme para a maioria das características estudadas.

As diferenças que ocorreram entre as estimativas dos quadrados médios do erro para 0 delineamento em blocos aumentados, podem ser consideradas homogêneas, pois o quociente entre o maior e o menor quadrado médio do erro, foi inferior a sete (Pimentel Gomes, 1990), exceto para peso médio de raízes cilíndricas comerciais (22) e porcentagem de raízes cilíndricas comerciais (14). 
Tabela 4. Média geral para as características avaliadas

\begin{tabular}{lccc}
\hline & \multicolumn{3}{c}{ Média Geral } \\
\cline { 2 - 4 } Características & DBC & BA $^{*}$ & BA2* $^{*}$ \\
\hline PTR & 5569,0430 & 7380,2796 & 3757,8026 \\
\% FLOR & 33,4300 & 30,5300 & 36,4800 \\
PMRCo & 91,6320 & 116,8425 & 65,3463 \\
\% RCO & 70,2600 & 62,5900 & 68,2600 \\
PMRCiCo & 76,1881 & 108,2388 & 44,4680 \\
\% RCiCo & 21,0400 & 26,6500 & 15,5500 \\
\hline
\end{tabular}

PIR: produçāo total de raízes

\%FLOR: porcentagem de florescimento prematuro

PMRCO: peso médio de raizes comerciais
\%RCo: porcentagem de raízes comerciais PMRCiCo: peso médio de raízes cilindricas comerciais \%RCiCo: porcentagem de raízes cilíndricas comerciais

BA 1: Delineamento em blocos aumentados no local ponte seca;

BA2: Delineamento em blocos aumentados no local genética;

DBC: Delineamento em blocos completos casualizados.

* médias ajustadas 
As médias gerais estimadas no delineamento de blocos casualizados foram intermediárias entre as obtidas nos locais BAI e $B A 2$, exceto para a porcentagem de raízes comerciais. Este comportamento das médias era esperado, devido às médias do delineamento de blocos casualizados terem sido obtidas pela média dos dois locais. No caso da porcentagem de raízes comerciais, esse fato não foi verificado, provavelmente pelo ajuste das médias, mostrando assim que o delineamento em blocos aumentados foi eficiente no controle local (Tabela 4).

Esses valores encontrados foram de menor magnitude do que os obtidos por Siqueira (1989), que estudou progênies da cultivar Campinas. Estas diferenças, talvez, estejam associadas a interação genótipo por ambiente, já que os ensaios foram realizados em região com temperaturas mais amenas.

Considerando-se os dois experimentos em blocos aumentados, verifica-se pela Tabela 4 , que as estimativas das médias do local BA2 foram menores do que as do local BA1, exceto para porcentagem de florescimento e porcentagem de raízes comerciais. No caso da porcentagem de florescimento os fatores indutivos como temperatura e fotoperíodo, e a idade fisiológica das plantas foram uniformes nos dois locais, enquanto que o efeito ambiental mais contrastante, o tipo de solo mais argiloso no local BA2, afetou $O$ desenvolvimento das raízes.

Esta discrepância entre os dois locais foi evidenciada, quando procedeu-se a análise dos dados em blocos casualizados e verificou-se que os valores de f para a fonte de variação blocos, foram altos.

As diferenças mais marcantes entre os dois locais, no tocante as estimativas das médias, ocorreu para produção total de raízes e peso médio de raízes cilíndricas comerciais, que foram 
superiores no BAl 1,96 e 2,43 vezes, respectivamente. Nota-se que as maiores diferenças estão associadas às características dos solos em cada local.

As médias de produção de raízes do local BAl, mostraram-se bastante próximas aquelas encontradas na literatura (Cotilho \& Churata-Masca, 1984; Faoro et al., 1985; Pessoa \& Cordeiro, 1986) e as médias do local BA2 foram bem menores, provavelmente devido a fatores comentados anteriormente.

As diferenças entre o peso médio de raízes cilíndricas comerciais nos locais, são próximas dos valores encontradas por Siqueira (1989).

A variância genética aditiva é a parte da variância genética que é responsável pelo progresso com a seleção através das gerações, nas espécies de propagação sexuada. Portanto é de grande importância para o melhorista durante o processo de seleção, na tentativa de obter populações melhoradas (Falconer, $1987)$.

Analisando a tabela 5, podemos verificar o acentuado efeito da interação genótipo por ambiente, pois elevadas estimativas da variância genética, foram observadas no local BA2, onde as médias foram menores (Tabela 4). Portanto a interação genótipo por ambiente inflaciona a variância genética, dificultando assim a seleção das plantas com melhor desempenho nos dois locais. Este fato é evidenciado principalmente para as caracteristicas associadas ao formato de raiz, que é altamente influenciado por condições de solo.

As estimativas da variância genética aditiva foram maiores nos ensaios analisados em blocos completos aumentados, do que no de blocos completos casualizados, pois neste último, os erros (residuo) foram muito altos. Somente a porcentagem de 
Tabela 5. Estimativas da variância genética presente para as características avaliadas.

\begin{tabular}{|c|c|c|c|}
\hline \multirow[b]{2}{*}{ Caracteristicas } & \multicolumn{3}{|c|}{ Variância genética } \\
\hline & $\overline{D B C}$ & $B A 1$ & $\overline{B A 2}$ \\
\hline$\overline{\text { PTR }}$ & 680360,23 & 1180864.24 & 1323321,64 \\
\hline$\%$ FLOR & 354,58 & 271,38 & 368,65 \\
\hline PMRCO & 49,08 & 438,78 & 357,37 \\
\hline FMRECico & $\begin{array}{l}0.809 \\
5,08\end{array}$ & $1,654,7 / 42$ & 295.639 \\
\hline \% RCiCo & $0.00^{1}$ & 185,63 & 184,89 \\
\hline
\end{tabular}

PTR: produção total de raízes

\%FLOR: porcentagem de florescimento prematuro

PMRCo: peso médio de raizes comerciais
\%RCo: porcentagem de raizes comerciais

PMRCiCo: peso médio de raizes cilindricas comerciais \%RCiCo: porcentagem de raizes cilíndricas comerciais

' estes valores foram considerados como zero.

BA1: Delineamento em blocos aumentados no local ponte seca;

BA2: Delineamento em blocos aumentados no local genética;

DBC: Delineamento em blocos completos casualizados. 
florescimento apresentou valor menor no local BAl, sendo a mesma de valor igual a 1085,52. Entretanto, o local BA2 apresentou magnitude próxima do delineamento de blocos casualizados (Tabela 6).

Foram obtidos valores negativos de variância genética para a porcentagem de raízes comerciais e o peso médio de raízes cilindricas comerciais, respectivamente $-24,69$ e $-13,28$ (Tabela 5). Estes resultados podem ser explicados segundo Ferreira (1996), por uma variabilidade muito grande dos dados ou o modelo utilizado para a interpretação dos dados experimentais não foi adequado. Também o tamanho da amostra (parcela) pode não ter sido suficiente, para um caráter mais restritivo como a porcentagem de raizes cilindricas comerciais. O mesmo autor sugere que adote-se o valor como zero, pois quando utilizou-se outro método para estimar os componentes da variância, como o da máxima verossimilhança restrita, este valor que foi negativo apresentou-se como zero. Desta forma, não foram obtidas as estimativas da variância genética e aditiva para a porcentagem de raízes comerciais e porcentagem de raizes cilíndricas comerciais.

Estes valores de variancia genética negativa, que foram considerados como zero e os que apresentaram baixa magnitude para o peso médio de raizes cilíndricas comerciais, provavelmente estejam associadas à interação genótipos por ambientes, pois estas características interagem de forma significativa com o ambiente, à não transformação dos dados e falta de repetibilidade, o que resultou em erros bem elevados.

As estimativas da variância genética aditiva foram mais uniformes entre os delineamentos estudados e nos diferentes locais apenas para a porcentagem de florescimento prematuro, devido ser esta uma característica que no presente trabalho, foi muito pouco 
Tabela 6. Estimativas da variância genética aditiva presente para as características avaliadas.

\begin{tabular}{lccc}
\hline & \multicolumn{3}{c}{ Variância genética aditiva } \\
\cline { 2 - 4 } Características & DBC & BA1 & BA2 \\
\hline PTR & 2721440,92 & 4723456,96 & 5293286,56 \\
\% FLOR & 1418,32 & 1085,52 & 1474,63 \\
PMRCo & 196,32 & 1755,12 & 1429,48 \\
\% RCo & 0,00 & 659,08 & 1182,52 \\
PMRCiCo & 20,36 & 4637,68 & 4373,16 \\
\% RCiCo & 0,00 & 742,52 & 739,56 \\
\hline
\end{tabular}

PIR: produção total de raízes

\%FLOR: porcentagem de florescimento prematuro

PMRCo: peso médio de raízes comerciais
\%RCo: porcentagem de raizes comerciais

PMRCiCo: peso médio de raízes cilíndricas comerciais \%RCiCo: porcentagem de raizes cilíndricas comerciais

BA1: Delineamento em blocos aumentados no local ponte seca;

BA2: Delineamento em blocos aumentados no local genética;

DBC: Delineamento em blocos completos casualizados. 
influenciada pelas condições experimentais(Tabela 6). Outro fato que também contribui para a uniformidade dos parâmetros entre os delineamentos, foi a forma de avaliação desta característica, pois não foram considerados diferentes padrões de florescimento e sim se a planta florescia prematuramente ou não.

Para a maioria das características avaliadas, houve pequena variação nos valores da variância genética aditiva nos dois locais, exceto para a porcentagem de raízes comerciais.

$\mathrm{Na}$ tabela 7 são mostradas as estimativas de herdabilidade com base na média das progênies avaliadas. Ocorreu uma ampla variação da estimativa de herdabilidade, entre as diversas características, principalmente no delineamento de blocos completos casualizados.

A ocorrência de baixas estimativas de herdabilidade nesse delineamento, para o peso médio de raízes cilíndricas comerciais e igual a zero para a porcentagem de raízes comerciais e porcentagem de raízes cilíndricas comerciais, é devido a fatores já comentados anteriormente na obtenção das estimativas da variância genética através da esperança do quadrado médio, pois a alta interação entre blocos e tratamentos, fez com o resíduo não fosse bem estimado.

As estimativas de herdabilidade obtidas no delineamento de blocos completos aumentados nos dois locais, mostraram-se de magnitude superior às estimativas obtidas no delineamento de blocos completos casualizados, cujas estimativas são oriundas do uso de repetições.

Os altos valores de herdabilidade encontrados para a maioria das características no local BAl, demonstram somente que o componente da interação genótipo por ambiente, foi bem 
Tabela 7. Estimativas de herdabilidade ao nível de médias de progênies para as características avaliadas.

\begin{tabular}{lccc}
\hline & \multicolumn{3}{c}{ herdabilidade (\%) } \\
\cline { 2 - 4 } Características & DBC & BA1 & BA2 \\
\hline PIR & 55,61 & 53,15 & 80,31 \\
\% FLOR & 96,97 & 74,43 & 97,59 \\
PMRCo & 17,28 & 65,33 & 82,11 \\
\% RCo & 0,00 & 47,60 & 89,85 \\
PMRCiCo & 0,82 & 88,96 & 95,14 \\
\% RCiCo & 0,00 & 79,93 & 84,41 \\
\hline
\end{tabular}

PTR: produção total de raízes

\%FLOR: porcentagem de florescimento prematuro

PMRCo: peso médio de raízes comerciais
\%RCo: porcentagem de raizes comerciais

PMRCiCo: peso médio de raizes cilíndricas comerciais

\%RCiCo: porcentagem de raizes cilíndricas comerciais

BA 1: Delineamento em blocos aumentados no local ponte seca;

BA2: Delineamento em blocos aumentados no local genética;

DBC: Delineamento em blocos completos casualizados. 
acentuado neste local.

As estimativas de herdabilidade foram maiores nos delineamentos de blocos aumentados para os caracteres, sendo de $97,59 \%, 89,85 \%$ e $95,14 \%$ respectivamente no local BA2. Neste local todas as estimativas de herdabilidade foram superiores ao local $B A 1$.

As estimativas de herdabilidade para porcentagem de florescimento prematuro, porcentagem de raízes comerciais e peso médio de raízes cilíndricas comercias no local BA2, apresentaram-se maiores e em alguns casos próximas dos resultados obtidos na literatura (Siqueira, 1989; Della Vecchia \& Pessoa, 1984), sendo que estes resultados também foram evidenciados por Momenté (1994) em batata, ou seja, estimativas de herdabilidade no delineamento de blocos aumentados de maior valor que os citados na literatura.

A porcentagem de florescimento apresentou uma maior proporcionalidade entre os resultados nos diferentes delineamentos e locais avaliados. Os altos valores de herdabilidade permitirão uma maior eficiência na seleção contra o florescimento prematuro, resultando em ganhos substanciais.

O coeficiente de variação genética mede o quanto da variação fenotípica é devido a fatores genéticos, sendo um importante parâmetro para uso do melhorista. Na tabela 8 são apresentados os coeficientes de variação genética encontrados nos diferentes delineamentos e locais estudados.

No delineamento de blocos completos casualizados, verificou-se que os coeficientes de variação genética foram de pequena magnitude. Somente a porcentagem de florescimento apresentou um valor de estimativa mais elevado, que foi de $56,3279 \%$, sendo superior ao valor de $32,47 \%$, encontrado por Siqueira 
Tabela 8. Coeficientes de variação genética para as caracteristicas avaliadas.

\begin{tabular}{lccc}
\hline & \multicolumn{3}{c}{ Coeficiente de Variação Genética (CVg) } \\
Características & DBC & BAl & BA2 \\
\cline { 2 - 4 } & 14,8112 & 14,7240 & 30,6125 \\
\% FLOR & 56,3279 & 53,9638 & 52,6336 \\
PMRCo & 7,6460 & 17,9277 & 28,9296 \\
\% RCo & 7,0736 & 20,5087 & 25,1885 \\
PMRCiCo & 2,9613 & 31,4586 & 74,3568 \\
\% RCiCo & 17,3236 & 51,1309 & 87,2257 \\
\hline
\end{tabular}

PTR: produçāo total de raizes

\%FLOR: porcentagem de florescimento prematuro PMRCo: peso médio de raizes comerciais
\%RCo: porcentagem de raizes comerciais PMRCiCo: peso médio de raizes cilindricas comerciais \%RCiCo: porcentagem de raizes cilindricas comerciais

BA1: Delineamento em blocos aumentados no local ponte seca;

BA2: Delineamento em blocos aumentados no local genética;

DBC: Delineamento em blocos completos casualizados. 
(1989). Isto demonstra que existe ainda uma grande variabilidade genética responsável pelo florescimento prematuro, necessitando portanto uma maior intensidade de seleção nestas progênies, contra o caráter, altamente indesejado entre os produtores.

Os menores valores observados para o peso médio de raízes comerciais e porcentagem de raízes comerciais, ocorreram devido a problemas na estimação dos componentes da variancia genética, comentados anteriormente. Entretanto o baixo valor encontrado para o peso médio de raízes cilíndricas comerciais esteja relacionado a intensa seleção que esta cultivar vem sendo submetida, como nos resultados obtidos por Mazurkiewicz (1973). Então, torna-se necessário utilizar de métodos que possibilitem um aumento da variabilidade genética para esse caráter e uma maior acurácia na seleção das melhores progênies.

No local BAl as estimativas do coeficiente de variação genética apresentaram magnitudes superiores às do delineamento de blocos completos casualizados, exceto para porcentagem de florescimento e produção total de raízes (Tabela 8). Os valores que mais se destacaram neste local foi a porcentagem de florescimento $(53,9638 \%)$ e porcentagem de raizes cilíndricas comerciais $(52,1309 \%)$, sendo estes percentuais da variação fenotípica devido a causas genéticas. Por sua vez, os resultados obtidos por siqueira (1989) apresentaram valores bem mais baixos, demostrando assim uma eficiência dos vários ciclos de seleção realizados ou somente a ocorrência de subestimadas, devido a interação dos tratamentos comuns com o bloco afetar a obtenção do erro experimental.

No local BA2 as estimativas foram superiores as do local BAl, com exceção apenas da porcentagem de florescimento prematuro, cuja diferença foi pequena. Nesse local destacaram-se as estimativas do coeficiente de variação genética, para o peso 
médio de raizes cilíndricas comerciais e porcentagem de raízes cilíndricas comerciais, com valores de $74,3568 \%$ e $87,2257 \%$, respectivamente (Tabela 8 ). Os menores valores das estimativas para a produção total de raízes, peso médio de raízes comerciais e porcentagem de raízes comerciais, sendo estes resultados concordantes com os obtidos por Siqueira (1989).

Pelas magnitudes dos coeficientes de variação genética para o local BA2, apesar de apresentar estimativas de médias menores do que o local BAl(Tabela 4), verificou-se que a variabilidade expressa para a maioria das características, foi devido principalmente a fatores genéticos presente nas progênies de meios irmãos em cenoura.

Os coeficientes de variação ambiental, expressam a precisão na qual o trabalho foi conduzido para cada uma das características avaliadas, refletindo assim os desvios da media sob a forma de variância, causada por diferenças genotípicas e de ambiente dentro das parcelas (Vencovsky, 1978).

Neste trabalho, as estimativas obtidas no delineamento de blocos aumentados, mostraram-se para todas as características uma menor magnitude, indicando assim que a princípio obteve-se uma melhor precisão experimental. No delineamento de blocos casualizados, os coeficientes para a porcentagem de raizes comerciais, porcentagem de raizes cilindricas comerciais apresentaram estimativas elevadas (Tabela 9). Para diminuir estes coeficientes de variação ambientale, consequentemente aumentar a precisão experimental, a literatura recomenda que se faça transformação dos dados para $\operatorname{arcsen}(x / 100)^{1 / 2}$. Desta forma, consegue-se aditividade e homogeneidade de variância. No presente trabalho nenhuma transformação de dados foi feita, para 
Tabela 9. Coeficientes de variação ambiental para as características avaliadas.

\begin{tabular}{|c|c|c|c|}
\hline \multirow[b]{2}{*}{ Características } & \multicolumn{3}{|c|}{$\begin{array}{c}\text { Coeficiente de Variação Ambiental (CVe) } \\
(\%)\end{array}$} \\
\hline & $\mathrm{DBC}$ & $B A$ & $\mathrm{BA2}$ \\
\hline PTR & 18,7122 & 13,8217 & 15.1534 \\
\hline$\%$ FLOR & 14,0649 & 1,6238 & 8,2549 \\
\hline PMRCo & 23,6517 & 13.0598 & 13,5018 \\
\hline \% RCo & 91,1508 & 21.5160 & 8.4633 \\
\hline PMRCiCo & 45,9873 & 11.0815 & 16,8042 \\
\hline$\%$ RCiCo & 73.1096 & 25,6183 & 37,4769 \\
\hline
\end{tabular}

PTR: produção total de raizes

\%FLOR: porcentagem de florescimento prematuro

PMRCo: peso médio de raízes comerciais
\%RCo: porcentagem de raizes comerciais

PMRCiCo: peso médio de raizes cilíndricas comerciais \%RCiCo: porcentagem de raizes cilindricas comerciais

BA 1: Delineamento em blocos aumentados no local ponte seca:

BA2: Delineamento em blocos aumentados no local genética;

DBC: Delineamento em blocos completos casualizados. 
que se pudesse ter uma idéia real da precisão experimental em todos os delineamentos.

Também o peso médio de raízes cilindricas comerciais, apesar de não ser expresso em porcentagem apresentou uma baixa precisão experimental (45,98\%), no delineamento de blocos completos casualizados. Este valor pode ser explicado através da elevada ação do ambiente na expressão desta característica (Marzurkiewcz, 1973), pois os dados utilizados para cada bloco, apresentavam uma grande variação.

Entre os resultados obtidos nas análises em blocos completos aumentados, verifica-se que a precisão experimental foi bem próxima nos dois locais, apenas para o peso médio de raízes comerciais (PMRCo), com valores de $13,05 \%$ e $13,50 \%$ para BAI e BA2, respectivamente. Este resultado é explicado pela maneira pela qual a característica foi obtida. Nela estão incluidas tanto raízes de formato cilíndrico e cônico, portanto as variações de condições de solo e irrigação pouco afetaram a obtenção desta característica nos dois locais.

No local BAl, houve melhor precisão experimental para peso médio de raízes cilíndricas comerciais (PMRCiCo), que foi de $11,08 \%$. O maior valor do coeficiente de variação ambiental foi para a porcentagem de raizes cilindricas comerciais, com 25,62\% (Tabela 9).

No local genética BA2 a menor e maior precisão experimental foram detectadas, respectivamente, para porcentagem de raizes cilindricas comerciais e porcentagem de florescimento (\%FLOR), com respectivos valores de $37,47 \%$ e $8,25 \%$ (Tabela 9). A maior precisão da porcentagem de florescimento prematuro, deve-se a interferência uniforme das condições de temperatura e fotoperíodo sobre o ensaio. 
Estas estimativas mostraram-se concordantes com as obtidas por Della Vecchia \& Pessoa (1984) e Siqueira (1989), com exceção para os valores em porcentagem, que no presente trabalho não foram transformados.

De maneira geral, para a maioria das características, o coeficiente de variação ambiental foi menor quando utilizou-se o delineamento em blocos aumentados. Este resultado, não é necessariamente vantajoso, uma vez que subestimativas do erro experimental podem estar ocorrendo. Portanto a maior precisão deste delineamento deve ser vista com uma certa cautela.

As diferenças dos valores do coeficiente de variação entre os locais no delineamento de blocos completos aumentados, sugere que esta diferenças estejam associadas a uma maior ou menor heterogeneidade em cada local.

As estimativas de b, que é a relação entre o coeficiente de variação genética e o coeficiente de variação ambiental, demonstram a potencialidade de seleção que uma determinada característica apresenta em uma população considerada. Os valores de b obtidos nesse trabalho, são mostradas na Tabela 10.

No delineamento de blocos completos aumentados os valores de $b$ foram todos menores do que um, exceto para $a$ característica porcentagem de florescimento, que foi de 4,0049. Os resultados evidenciam que o uso do delineamento de blocos completos aumentados acentua a chance de se obter sucesso durante o processo de seleção.

As estimativas de $b$ no local BA l, foram todas superiores $a$ unidade, com exceção da porcentagem de raizes comerciais, cujo valor de 0,9532 foi próximo de um. O maior valor de b foi 
Tabela 10. Estimativas de b (relação entre CVg e CVe) para as características avaliadas.

\begin{tabular}{lccc}
\hline & \multicolumn{3}{c}{$b$} \\
Características & DBC & BA1 & BA2 \\
\cline { 2 - 4 } \% FLOR & 0,7915 & 1,0653 & 2,0202 \\
PMRCo & 4,0049 & 1,7064 & 6,3761 \\
\% RCO & 0,3233 & 1,3727 & 2,1426 \\
PMRCiCo & 0,0699 & 0,9532 & 2,9762 \\
\% RCiCo & 0,0644 & 2,8388 & 4,4229 \\
\hline
\end{tabular}

PTR: produçāo total de raízes

\%FLOR: porcentagem de florescimento prematuro

PMRCo: peso médio de raizes comerciais
\%RCo: porcentagem de raízes comerciais

PMRCiCo: peso médio de raízes cilíndricas comerciais

\%RCiCo: porcentagem de raízes cilíndricas

comerciais

BA 1: Delineamento em blocos aumentados no local ponte seca;

BA2: Delineamento em blocos aumentados no local genética;

DBC: Delineamento em blocos completos casualizados. 
obtido para o peso médio de raízes cilíndricas comerciais (PMRCiCo), que foi de 2,8388. Outras estimativas de $b$ bastante acentuadas foram as de porcentagem de raízes cilíndricas comerciais (\%RCiCo) e porcentagem de florescimento (\%FLOR), que apresentaram valores de 1,9959 e 1,7064, respectivamente (Tabela 10).

Esses valores indicam uma situação muito favorável a seleção de plantas superiores, podendo ser obtidas progênies com raízes cilíndricas de tamanho comercial e com baixo índice de florescimento prematuro.

No local BA2, as estimativas mais pronunciadas foram para as características porcentagem de florescimento (\%FLOR) e peso médio de raízes cilíndricas comerciais (PMRCiCo), as quais apresentaram magnitudes de 6,3761 e 4,4229, respectivamente.

Estes resultados são semelhantes aos obtidos no local $B A 1$, indicando que pode ocorrer uma seleção eficiente para estas características nos dois locais. Por sua vez, a menor estimativa foi a encontrada para produção total de raízes, que foi de 1,7304. As demais características apresentaram estimativas com magnitudes entre 2 e 3 (Tabela 10), indicando uma possibilidade de maior sucesso ao se praticar seleção neste local.

Entre os dois locais (BAl e BA2), somente a porcentagem de raizes cilíndricas comerciais, forneceu estimativas com valores próximos. Os valores de b obtidos no presente trabalho, foram bem superiores aos encontrados por Siqueira (1989). Estes resultados podem estar relacionados à maior expressão da variabilidade genética nas progênies, devido principalmente ao efeito da interação genótipo por ambiente, que aumentou a variância genética.

A tabela 11 apresenta os valores de ganho com a seleção (GS) das progênies em comparação com a população 
Tabela 11. Ganhos com a seleção (GS) para as características avaliadas.

\begin{tabular}{lccc}
\hline & \multicolumn{3}{c}{ GS $(\%)$} \\
\cline { 2 - 4 } Características & DBC & BA1 & BA2 \\
\hline PTR & 11,6598 & 14,3976 & 6,6083 \\
\% FLOR & $-54,7805$ & $-53,4942$ & $-55,5951$ \\
PMRCo & 18,3223 & 47,0565 & $-12,3720$ \\
\% RCO & 67,5990 & 16,7289 & 18,4411 \\
PMRCiCo & 20,2024 & 52,1041 & $-20,6053$ \\
\% RCiCo & $-2,5448$ & 16,2937 & $-24,2575$ \\
\hline
\end{tabular}

PTR: produção total de raízes

\%FLOR: porcentagem de florescimento prematuro

PMRCo: peso médio de raizes comerciais
\%RCo: porcentagem de raizes comerciais PMRCiCo: peso médio de raizes cilindricas comerciais \%RCiCo: porcentagem de raizes cilindric as comerciais

BA1: Delineamento em blocos aumentados no local ponte seca;

BA2: Delineamento em blocos aumentados no local genética;

DBC: Delineamento em blocos completos casualizados. 
original da cultivar Campinas. Para a produção total de raízes o ganho com a seleção calculado no delineamento de blocos completos casualizados (11,6598\%), mostrou-se similar ao do local BA1 (14,3976\%), e para o local BA2 ocorreu uma estimativa de ganho bem menor $(6,6083 \%)$. Estes valores pequenos de ganhos obtidos com a seleção para a produção de raízes estão relacionados com a herança poligênica e a grande influência do ambiente na expressão do caráter.

Em relação à porcentagem de florescimento, houve concordância entre as porcentagens de ganho nos diversos locais e delineamentos estudados, sendo que todas ficaram próximas a $-55 \%$ (Tabela 11). Os valores foram negativos porque neste caráter, o sucesso está na diminuição da taxa de florescimento prematuro e não por ineficiência durante os vários ciclos de seleção. Portanto a seleção contra o florescimento prematuro, deve ser realizada em locais e épocas de plantio, que satisfaçam as condições de temperaturas amenas e ou fotoperiodismo mais longo.

Para o peso médio de raízes comerciais os ganhos com a seleção foram de $18,3223 \%$ no delineamento de blocos completos casualizados, $47,0565 \%$ no local BAl e de $-12,3720 \%$ no local BA2. A variação dos ganhos nos diferentes locais está associada ao desempenho médio da população Campinas, ou seja nos locais onde sua média foi menor, os ganhos tenderam a serem maiores (Tabela 11). Verifica-se que no local BA2, o comportamento médio da população original Campinas, foi superior a média das progênies, resultando assim em um ganho negativo. Para evitar este problema, deve-se realizar ensaios em vários locais e a partir de uma análise conjunta, obter ganhos com a seleção mais próximos da realidade.

Os ganhos para porcentagem de raízes comerciais, foram todos positivos, mas houve discrepância nos resultados. No 
delineamento de blocos completos casualizados, o ganho foi de $67,5990 \%$, em média 3,8 vezes maior do que nos ensaios em blocos completos aumentados em ambos os locais, sendo de $16,7289 \%$ para o local BAl e 18,4411\% para o local BA2 (Tabela 11).

Não houve uma coincidência entre os ganhos com a seleção para o peso médio de raízes cilíndricas comerciais. O ganho foi positivo para o delineamento de blocos completos casualizados e blocos completos aumentados no local BAl e negativo no local BA2.

A porcentagem de raízes cilíndricas comerciais, apresentou uma grande discrepancia tanto em valor, como em sinal (Tabela 11).

Essas variações que ocorreram para estas características relacionadas com o formato, eram até certo ponto esperadas, devido ao grande efeito do ambiente, principalmente condições de solo e cultivo, na produção de raízes cilíndricas. Ressalta-se então a necessidade repetição do ensaio em um maior número de locais, fornecendo assim estimativas do ganho mais precisas para estas características ligadas ao formato da raiz.

Portanto, valores menores ou maiores de ganho com a seleção para todas as características analisadas, dá apenas uma idéia do ganho possível obtido com a seleção, em função das condições em que foram executados e analisados os ensaios.

- ganho para produção total de raízes foi semelhante aos encontrados por Siqueira (1989), mas ocorreu uma discordância em relação à porcentagem de florescimento prematuro, peso médio de raízes cilíndricas comerciais e porcentagem de raízes cilíndricas comerciais, provavelmente devido a esses resultados obtidos pelo autor serem estimativas e, também, aos fatores citados anteriormente. 
Os coeficientes de correlação de Spearman entre as médias estimadas no delineamento de blocos completos casualizados e as médias ajustadas pelo delineamento de blocos completos aumentados, nos dois locais, são apresentadas na Tabela 12.

As estimativas de correlação de Spearman, para a maioria das características avaliadas apresentaram valores bastante satisfatórios (superiores a 0,50) para os dois locais (Tabela 12). Os resultados demonstram que a ordem das progênies pouco se altera na comparação entre o delineamento de blocos completos casualizados, utilizado como padrão, e os delineamentos de blocos completos aumentados. Estes resultados foram semelhantes ao encontrados por Souza (1997) para avaliação de progênies de eucalipto e feijão.

Para a produção total de raízes o coeficiente de correlação para o local BAl foi de 0,6697 e de 0,7997 para o local BA2 (Tabela 12). Verifica-se que o local BA2 apresentou médias menores do que BAl, mas maior concordancia com o posicionamento das médias no delineamento de blocos completos casualizados.

A porcentagem de florescimento foi a característica que apresentou os maiores valores de concordância das médias do delineamento em blocos aumentados com as médias do delineamento padrão. A correlação de Spearman esteve próxima de um, como pode ser visto na Tabela 12. Esses resultados evidenciam a pequena influência das condiçōes edáficas nesta característica e a influência do clima de maneira uniforme nos dois locais.

Em relação ao peso médio de raizes comerciais, houve uma pequena diferença entre os dois locais (BAl e BA2), enquanto que para a porcentagem de raizes comerciais os valores foram 
Tabela 12. Coeficientes de correlação de Spearman entre as médias estimadas no delineamento de blocos completos casualizados e as estimadas através da estratégia de blocos aumentados para as características avaliadas.

\begin{tabular}{lcc}
\hline & \multicolumn{2}{c}{ Correlação de Spearman } \\
\cline { 2 - 3 } Características & BA1 & BA2 \\
\hline PTR & 0,6697 & 0.7997 \\
\% FLOR & 0,9561 & 0.9728 \\
PMRCo & 0,7355 & 0,6402 \\
\% RCo & 0.6521 & 0.6574 \\
PMRCiCo & 0.5566 & 0.7576 \\
\% RCiCo & 0.7023 & 0.6340 \\
\hline
\end{tabular}

PTR: produção total de raízes

\%FLOR: porcentagem de florescimento prematuro

PMRCo: peso médio de raizes comerciais
\%RCo: porcentagem de raizes comerciais

PMRCiCo: peso médio de raízes cilíndricas comerciais \%RCiCo: porcentagem de raizes cilindricas comerciais

BA I: Delineamento em blocos aumentados no local ponte seca;

BA2: Delineamento em blocos aumentados no local genética; 
extremamente próximos, ficando em torno de 0,6500 (Tabela 12). Desta forma, as condições que afetam o desenvolvimento das raízes, foram relativamente proporcionais para os dois locais.

Ocorreu com o peso médio de raízes cilíndricas comerciais a maior diferença entre os dois locais, sendo que no local BAl a correlação foi de 0,5566 enquanto que no local BA2 foi de 0,7576 . Esta diferença de 0,2010 entre os dois locais, demonstra o elevado efeito da interação genótipo por ambiente para esta característica associada ao formato cilíndrico da raiz.

Diante desses resultados verifica-se que o delineamento em blocos completos aumentados, mostrou-se eficiente no diz respeito a hierarquia das médias das progênies nos diferentes locais, quando comparado com as médias obtidas no delineamento de blocos completos casualizados. Neste, as médias foram obtidas através de repetições, enquanto que no caso de blocos aumentados elas foram ajustadas, através do comportamento das testemunhas nos diferentes blocos.

Portanto, deve-se utilizar como testemunhas, materiais geneticamente uniformes, como híbridos e clones, onde a variação encontrada nas testemunhas entre os blocos, é somente devido a fatores ambientais.

Deve-se ressaltar, que nem sempre é importante que ocorra coincidencia entre as médias das progênies. O objetivo é poder selecionar as de melhor performance agronômica, tanto com a utilização de um delineamento experimental, como de outro. Portanto verificou-se $\circ$ índice de coincidencia das médias entre $\circ$ delineamento em blocos aumentados, e o considerado padrão, em diferentes intensidades de seleção.

De acordo com a tabela 13 verificou-se que no local BA 1 , o índice de coincidência foi de $70 \%$, quando o nível de pressão de 
seleção foi de $44,44 \%$. Quando selecionaram-se $55,55 \%$ das progênies o índice de coincidência foi de $78 \%$, sendo que o ganho de $8 \%$ foi muito pequeno, quando aumentou-se apenas em $10 \%$ o número de indivíduos selecionados.

Considerando-se as progênies que apresentaram os maiores valores de porcentagem de florescimento prematuro, que neste caso é indesejável, com 22,22\% das progênies de maiores valores, o índice de coincidência foi de $95 \%$ (Tabela 13), mostrando assim que o delineamento de blocos completos aumentados é eficiente quando há pouca interferência do ambiente na expressão da característica, como foi demonstrado pelas outras estimativas já discutidas.

Para o peso médio de raízes comerciais o índice de 73,33 \% de coincidência das médias superiores, foi razoável considerandose apenas as 33,33 \% médias superiores. Para a porcentagem de raízes comerciais houve magnitudes menores de coincidencia dentro de cada porcentagem considerada de progênies superiores (Tabela 13).

A alta influência do ambiente no peso médio de raízes cilíndricas comerciais, foi evidenciado pelos menores índices de coincidência, chegando a um nível satisfatório somente com uma suave intensidade de seleção $(44,44 \%)$. Possivelmente, muitas raízes não incluídas no padrão de cilíndricas comerciais, podem ser geneticamente cilíndricas, mas as condições de solo podem impedir o desenvolvimento secundário, e consequentemente estas raízes se apresentarem cônicas.

Ocorre uma coincidência de médias superiores maior do que $70 \%$, quando se considerou $44,44 \%$ de seleção das melhores 
Tabela 13. Índice de coincidência (IC) entre as médias superiores do delineamento de blocos completos casualizados e blocos aumentados no local BAI para as características avaliadas.

\begin{tabular}{|c|c|c|c|c|c|}
\hline \multirow[b]{3}{*}{ Características } & \multicolumn{5}{|c|}{ IC (\%) } \\
\hline & \multicolumn{5}{|c|}{ Porcentagem de progênies selecionadas } \\
\hline & 11,11 & 22,22 & 33,33 & 44,44 & 55,55 \\
\hline PTR & 50,00 & 60,00 & 66,66 & 70,00 & 78,00 \\
\hline$\%$ FLOR & 60,00 & 95,00 & 96.66 & 95,00 & 92,00 \\
\hline PMRCO & 60,00 & 60,00 & 73.33 & 77.50 & 78.00 \\
\hline$\%$ RCo & 60,00 & 50,00 & 53,33 & 62,50 & 76,00 \\
\hline PMRCiCo & 50,00 & 45,00 & 50,00 & 65,00 & 66.00 \\
\hline$\%$ RCiCo & 40.00 & 60,00 & 63,33 & 72,50 & 80,00 \\
\hline
\end{tabular}

PTR: produçāo total de raízes

\%FLOR: porcentagem de florescimento prematuro

PMRCo: peso médio de raizes comerciais
\%RCo: porcentagem de raízes comerciais

PMRCiCo: peso médio de raízes cilíndricas comerciais

\%RCiCo: porcentagem de raízes cilindricas

comerciais 
progênies, para a porcentagem de raízes cilíndricas comerciais (Tabela 13). Estes resultados obtidos no local BA1, indicam, que a eficiência do delineamento em blocos aumentados ocorre somente quando utiliza-se menores intensidades de seleção em caracteres muito influenciados pelo ambiente. Já quando há pouca influência do ambiente, ou esta ocorre de maneira uniforme, pode-se utilizar de maior pressão de seleção, que a coincidência das médias se mantém de maneira satisfatória.

Já no local BA2, os resultados apresentaram-se similares (Tabela 14) aos obtidos no local BA1, quando se compara os índices de coincidência das médias superiores em várias condições de pressão de seleção.

Apenas a produção total de raízes apresentou uma coincidência de médias superiores de $76,66 \%$, ao nível de $33,33 \%$, superando os resultados obtidos no local BAl.

A porcentagem de florescimento prematuro apresentou comportamento semelhante nos dois locais, mas no local BA2 ocorreram magnitudes menores de coincidência, sendo esta diminuição pouco proeminente (Tabela 14). Este resultados demonstram que os fatores indutivos do florescimento, como temperatura e fotoperíodo, agiram de maneira semelhante nos dois locais.

O peso médio de raízes comerciais e a porcentagem de raizes comerciais, apresentaram um índice de coincidência de $70 \%$, quando foi utilizado para as duas características uma intensidade de seleção de 44,44\%. Já o maior nível de coincidência no local BA2, foi encontrado para o peso médio de raízes cilíndricas comerciais, onde $76,66 \%$ das progênies apresentaram o mesmo desempenho médio nos dois delineamentos comparados. A porcentagem de raizes cilindricas comerciais só atingiu o nível de $70 \%$ de coincidência, 
Tabela 14. Índice de coincidência (IC) entre as médias superiores do delineamento de blocos completos casualizados e blocos aumentados no local BA2 para as características avaliadas.

\begin{tabular}{|c|c|c|c|c|c|}
\hline \multirow[b]{3}{*}{ Características } & \multicolumn{5}{|c|}{ IC (\%) } \\
\hline & \multicolumn{5}{|c|}{ Porcentagem de progênies selecionadas } \\
\hline & 11,11 & 22,22 & 33,33 & 44,44 & 55,55 \\
\hline PTR & 50,00 & 65,00 & 76,66 & 82,50 & 84,00 \\
\hline$\%$ FLOR & 80,00 & 90,00 & 90,00 & 90,00 & 92,00 \\
\hline PMRCO & 40,00 & 50,00 & 63,33 & 70,00 & 72,00 \\
\hline$\%$ RCo & 30,00 & 45,00 & 63,33 & 70,00 & 82,00 \\
\hline PMRCiCo & 60,00 & 80,00 & 76,66 & 75.00 & 82,00 \\
\hline$\%$ RCiCo & 40,00 & 60,00 & 63,33 & 70,00 & 70,00 \\
\hline
\end{tabular}

PTR: produção total de raízes

\%FLOR: porcentagem de florescimento prematuro PMRCo: peso médio de raízes comerciais
\%RCo: porcentagem de raizes comerciais

PMRCiCo: peso médio de raízes cilíndricas comerciais

\%RCiCo: porcentagem de raizes cilíndricas comerciais 
quando selecionou-se as 44,44\% progênies superiores, demonstrando o acentuado efeito do ambiente na expressão desta característica.

Observando os resultados, verifica-se que, nos dois locais, houve maior coincidencia entre as médias de ambos os delineamentos, quanto maior for $\circ$ número de progênies selecionadas para caracteres com acentuado efeito do ambiente. Dessa forma, quando o melhorista utilizar o delineamento de blocos aumentados na avaliação de progênies de cenoura, deverá praticar seleção com menor intensidade.

É importante ressaltar que a coincidência entre as médias deve ser considerada também em relação as progênies que apresentam médias menores, dependendo do caráter a ser selecionado. No caso da porcentagem de florescimento prematuro, quanto menor for o valor, melhor será a desempenho dessa progênie.

$\mathrm{Na}$ Tabela 15, estão os índices de coincidencia para o local BAl, considerando as progênies que apresentaram as menores médias ou seja, as progênies inferiores.

Quando consideramos uma alta pressão de seleção na porcentagem de florescimento prematuro, verificamos que a coincidência das médias inferiores (desejável), são bem menores do que quando comparado com a coincidencia das médias superiores. Esses resultados demonstram a necessidade de se utilizar intensidades de seleção mais brandas quando se quer selecionar plantas com menor incidencia de florescimento prematuro. Desta forma diminui-se o efeito da interação genótipo por ambiente no processo de seleção.

No local BA2, o comportamento foi bastante semelhante ao do local BAl. À medida que se aumentou a pressão de seleção o índice de coincidência diminuiu entre as médias menores. Para o 
Tabela 15. Índice de coincidência (IC) entre as médias inferiores do delineamento de blocos completos casualizados e blocos aumentados no local BAI para as características avaliadas.

\begin{tabular}{|c|c|c|c|c|c|}
\hline \multirow[b]{3}{*}{ Características } & \multicolumn{5}{|c|}{$\mathrm{IC}(\%)$} \\
\hline & \multicolumn{5}{|c|}{ Porcentagem de progênies selecionadas } \\
\hline & 11,11 & 22,22 & 33,33 & 44,44 & 55,55 \\
\hline PTR & 30,00 & 45,00 & 53,33 & 62,50 & 62,00 \\
\hline$\%$ FLOR & 60,00 & 40,00 & 46,66 & 52,50 & 64,00 \\
\hline PMRCO & 30,00 & 25,00 & 56,00 & 60,00 & 64,00 \\
\hline$\%$ RCo & 10,00 & 15,00 & 26,66 & 47,50 & 66,00 \\
\hline PMRCiCo & 30,00 & 35,00 & 43,33 & 45,00 & 60,00 \\
\hline \% RCiCo & 20,00 & 20,00 & 36,66 & 55,00 & 62,00 \\
\hline
\end{tabular}

PTR: produçāo total de raizes

\%FLOR: porcentagem de florescimento prematuro PMRCo: peso médio de raizes comerciais
\%RCo: porcentagem de raízes comerciais

PMRCiCo: peso médio de raízes cilíndricas comerciais

\%RCiCo: porcentagem de raízes cilíndricas comerciais 
peso médio de raízes comerciais quando utilizou-se uma pressão de seleção de $11,11 \%$ não ocorreu nenhuma coincidência entre as médias (Tabela 16).

A porcentagem de florescimento prematuro, apresentou comportamento semelhante ao do local BAl, quando comparou-se o indice de coincidência tanto nas médias superiores, como nas inferiores.

Além da coincidência entre as médias é importante que se calcule a eficiência de seleção, pois uma parte desta coincidência pode ser aleatória.

A eficiência de seleção para o local BAl, segundo o método proposto por Hamblin \& Zimmermann (1986), mostrou-se razoável para a maioria das características (Tabela 17), quando utilizou-se uma intensidade de seleção de $33,33 \%$ e 44,44\%. As estimativas de eficiência de seleção apresentaram valores médios de 30 a 50\%. Esse resultado deve estar relacionado com a baixa expressão da variabilidade genética, discutido no item relativo aos coeficientes de variação genética e o efeito acentuado da interação genótipo por ambiente. Portanto para diminuir a possibilidade de erros, durante o processo de seleção com o uso de blocos aumentados, deve-se procurar utilizar intensidades de seleção mais brandas.

As estimativas de eficiência com a seleção no local BA2, mostraram maior magnitude do que no local BAl. Este resultado ressalta o alto efeito da interação genótipo por ambiente na maior expressão da variabilidade das progênies de meios irmãos de cenoura neste local.

Também os melhores níveis de eficiência de seleção, como pode ser visto na tabela 18, ocorreram quando a intensidade 
Tabela 16. Índice de coincidência (IC) entre as médias inferiores do delineamento de blocos completos casualizados e blocos aumentados no local BA2 para as características avaliadas.

\begin{tabular}{|c|c|c|c|c|c|}
\hline \multirow[b]{3}{*}{ Características } & \multicolumn{5}{|c|}{ IC (\%) } \\
\hline & \multicolumn{5}{|c|}{ Porcentagem de progênies selecionadas } \\
\hline & 11.11 & 22,22 & 33,33 & 44,44 & 55,55 \\
\hline PTR & 10,00 & 30,00 & 46,67 & 62,50 & 62,00 \\
\hline$\%$ FLOR & 60,00 & 45,00 & 53,33 & 57,50 & 72,00 \\
\hline PMRCO & 0,00 & 25,00 & 50,00 & 47,50 & 56,00 \\
\hline$\%$ RCo & 10,00 & 15,00 & 23,33 & 47,50 & 66,00 \\
\hline PMRCiCo & 20,00 & 25,00 & 33,33 & 45,00 & 56,00 \\
\hline$\%$ RCiCo & 20,00 & 20,00 & 36,66 & 55,00 & 62,00 \\
\hline
\end{tabular}

PTR: produçāo total de raízes

\%FLOR: porcentagem de florescimento prematuro

PMRCo: peso médio de raízes comerciais
\%RCO: porcentagem de raízes comerciais

PMRCiCo: peso médio de raízes cilíndricas comerciais

\%RCiCo: porcentagem de raízes cilíndricas comerciais 
Tabela 17. Eficiência de seleção (ES) estimada em relação ao delineamento de blocos completos casualizados e blocos aumentados no local BAI para as características avaliadas.

\begin{tabular}{|c|c|c|c|c|c|}
\hline \multirow[b]{3}{*}{ Características } & \multicolumn{5}{|c|}{$E S(\%)$} \\
\hline & \multicolumn{5}{|c|}{ Porcentagem de progênies selecionadas } \\
\hline & 11,11 & 22,22 & 33,33 & 44,44 & 55,55 \\
\hline PTR & 43,75 & 48,57 & 49,95 & 46,00 & 50,50 \\
\hline$\%$ FLOR & 77,50 & 87,14 & 85,00 & 82,00 & 81,90 \\
\hline PMRCO & 32,50 & 35,71 & 45,00 & 46,00 & 36.99 \\
\hline$\%$ RCo & 21,25 & 29,28 & 45,00 & 46,00 & 59,49 \\
\hline PMRCiCo & 55,00 & 74,28 & 65,00 & 55,00 & 59,49 \\
\hline$\%$ RCiCo & 32,50 & 48,57 & 45,00 & 46,00 & 32,49 \\
\hline
\end{tabular}

PTR: produção total de raizes

\%FLOR: porcentagem de florescimento prematuro

PMRCo: peso médio de raizes comerciais
\%RCo: porcentagem de raizes comerciais

PMRCiCo: peso médio de raizes cilindricas comerciais

\%RCiCo: porcentagem de raizes cilindricas

comerciais

' progênies superiores 
Tabela 18. Eficiência de seleção (ES)estimada em relação ao delineamento de blocos completos casualizados e blocos aumentados no local BA2 para as características avaliadas.

\begin{tabular}{lccccc}
\hline & \multicolumn{5}{c}{ ES $(\%)$} \\
\cline { 2 - 6 } Características & 11,11 & 22,22 & 33,33 & 44,44 & 55,55 \\
\cline { 2 - 6 } & 43,75 & 55,00 & 55,00 & 68,00 & 59,00 \\
\% F FLOR & 55,00 & 93,57 & 95,00 & 91,00 & 81,90 \\
PMRCo & 55,00 & 48,57 & 60,00 & 59,00 & 50,49 \\
\% RCo & 55,00 & 35,71 & 30,00 & 32,50 & 45,99 \\
PMRCiCo & 43,75 & 29,28 & 25,00 & 37,00 & 23,49 \\
\% RCiCo & 32,50 & 48,57 & 45,00 & 50,50 & 54,49 \\
\hline
\end{tabular}

PTR: produção total de raízes

\%FLOR: porcentagem de florescimento prematuro

PMRCo: peso médio de raízes comerciais
\%RCo: porcentagem de raízes comerciais

PMRCiCo: peso médio de raízes cilíndricas comerciais \%RCiCo: porcentagem de raizes cilíndricas comerciais 
de seleção esteve em torno de 33,33 a 44,44 \%, ou seja menores pressões de seleção, concordando com os resultados obtidos para a seleção de progênies de feijão e eucalipto no delineamento de blocos aumentados (Souza, 1989).

Portanto nas condições em que foram realizadas os ensaios, os resultados demonstram a viabilidade do uso do delineamento de blocos aumentados em programas de melhoramento de cenoura. 
Considerações gerais

Em função dos resultados obtidos, verificou-se que o delineamento de blocos aumentados é uma importante alternativa no processo de seleção de genótipos de cenoura, principalmente quando se quer apenas descartar os piores materiais. Este processo normalmente é realizado nas etapas iniciais dos programas de melhoramento.

A partir de um único cruzamento, uma quantidade razoável de famílias a ser avaliadas situa-se em torno de 100. Entretanto, no início de um programa de seleção o melhorista faz muitos cruzamentos, o que resultará em um grande número de populações segregantes. Normalmente esta avaliação de um grande número de progênies é realizado de uma única vez.

Em função disso, o uso de blocos aumentados nas fases iniciais, permitirá a avaliação de um maior número de progênies ou famílias, com considerável redução na quantidade de recursos financeiros e de mão de obra, quando comparado com o uso de delineamentos como o de blocos completos casualizados.

A instalação e planejamento dos experimentos em blocos aumentados é outra vantagem importante, que foi verificada durante a instalação e condução do presente trabalho, mostrando ser de extrema facilidade.

Outro ponto que também deve ser considerado é que a perda de parcelas com tratamentos regulares durante a condução dos experimentos não proporciona maiores problemas para a análise estatística dos dados, apesar disso não ter ocorrido no presente trabalho. Este fato possibilita, ainda, o descarte de materiais relacionados a características que possam ser avaliadas no campo 
como por exemplo, o florescimento prematuro e susceptibilidade a uma determinada doença. Com isso, haverá uma redução do número de famílias ou progênies a serem avaliadas.

A obtenção de parâmetros genéticos no delineamento em blocos aumentados é um ponto importante a ser considerado, pois normalmente eles apresentam valores maiores do que o delineamento em blocos casualizados, como pode ser visto nos resultados obtidos no presente trabalho. Esses valores altos de estimativas de parâmetros genéticos, também foram encontrado por Bearzoti (1994) e Gomes (1995), na avaliação de clones de batata. Portanto as estimativas dos parâmetros genéticos obtidos com o delineamento de blocos aumentados devem ser consideradas com uma certa cautela.

Bearzoti (1994) sugeriu que as estimativas podem apresentar resultados mais precisos, com o desenvolvimento de um método de recuperação da informação interblocos, da mesma maneira como se faz quando se utiliza o delineamento de blocos incompletos.

Além do uso de blocos aumentados, como estratégia de avaliação de progênies nas fases iniciais de programas de melhoramento, ele deve ser usado como forma de controlar a heterogeneidade do solo.

No presente trabalho apesar das testemunhas utilizadas, as cultivares Nantes e Brasilia serem amplamente conhecidas pela sua performance em várias regiões e épocas de cultivo, as testemunhas devem ser mais uniformes (híbridos ou clones), detectando de maneira mais eficiente variações ambientais.

O delineamento de blocos aumentados, mostrou-se mais eficiente para características que são pouco influenciadas pelo 
ambiente, ou a influência é mais geral, como foi o caso da porcentagem de florescimento prematuro.

A utilização de métodos de análise espacial, que tem mostrado serem eficientes para a melhoria da precisão experimental, não apresentam vantagem quanto a economia de custos dos blocos aumentados, pois o delineamento a ser utilizado deve ser 0 de blocos casualizados. 


\section{CONCLUSÕES}

1. O uso do delineamento em blocos aumentados, mostrou-se viável para uso nas fases iniciais de programas de melhoramento genético de cenoura, com intensidades de seleção mais brandas.

2. Os parâmetros genéticos estimados nos delineamentos em blocos aumentados, na maioria das características avaliadas foram de maior magnitude, devendo ser consideradas com alguma cautela.

3. A coincidência entre as médias dos blocos aumentados e os valores de correlação com o delineamento em blocos casualizados, foram de maneira geral, de magnitudes elevadas.

4. Os vários ciclos de seleção massal mostraram-se eficientes em função dos ganhos obtidos, porém ainda existe variabilidade suficiente para praticar seleção nestas progênies. 


\section{REFERÊNCIAS BIBLIOGRÁFICAS}

BANGA, 0. Origin of the European cultivated carrot. Euphytica, v.6, p.54-63, 1957.

BANGA, O. In: SIMMONDS, N. W. (Ed.) Evolution of crop plants. New York: Longman, 1976. p.291-293.

BANGA, O. Selection of carrots for carotene content: Il: Sub-normal content at low temperature. Euphytica, v.4, p.183-189, 1955.

BARBOSA, M. H. P. Capacidade combinatória e comparação entre critérios de seleção de clones de batata (Solanum fuberosum L.). Lavras, 1996, $141 \mathrm{p}$. Tese (Doutorado) - Universidade Federal de Lavras.

BARNES, W. C. Effects of some enviromental factors on growth and color of carrots. Cornell University Agriculture Experimentation Mem.n.186. 1936.36p.

BEARZOTI, E. Comparação entre métodos estatísticos na avaliação de clones de batata em um programa de melhoramento. Lavras, 1994. 128p. Dissertação (M.S.) - Escola Superior de Agricultura de Lavras. 
BRAAK, J.; CHO, Y. O. Some observations on the floral biology of the carrot (Daucus carota L.). Euphytica, v.7, p.131-139, 1958.

BRAR, J.S. ; SUKHIJA, B.S. Studies on genetic parameters in carrot (Daucus carota L.). Journal Research Punjab Agricultural University, v.18, n.3, p.287-291, 1981.

BRAR, J.S. ; SUKHIJA, B.S. Variability, heritability and genetic advance in carrot (Daucus carota L.). Journal Research Punjab Agricultural University, v.17, n.4, p.442-443, 1980.

BRIM, C. A. Quantitative genetics and breeding. In: BERNARD, R. L. \& WEISS, M. G., ed. Soybeans; improvement production and uses. Madison, American Society of Agronomy, 1973. cap.5, p. 155-85.

BUSO, J.A. Estimativas de parâmetros qenéticos de caracteres de plantas e bulbo de cebola (Allium cepa L.). Piracicaba, 1978. 132p. Dissertação (M.S.) - Escola Superior de Agricultura "Luiz de Queiroz", Universidade de São Paulo.

CAMARGO, L. S. As hortaliças e seu cultivo. Campinas: Fundação Cargill, 1984, $321 \mathrm{p}$.

CASALI, V.W.D.; PINTO, C.M.F.; PADUA, J.G. Origem e botânica da cenoura. Informe Aqropecuário, v.10, n.120, p. 8-9, 1984. 
COCKERHAM, C. C. Estimation of genetic variance. In: HANSON, W.D.; ROBINSON, H.F. (Ed.) Statistical genetics and plant breeding. Washington: National Academic Science National Research Council, 1963. p. 53-93.

COSTA, C.P. Cenoura Nacional, um germoplasma para as condições de dias curtos nas regiões tropicais e sub-tropicais. Relatório Científico Departamento de Genética. ESALQ/USP, v.8: p.50-51, 1974.

COtIlHo, M. R.; ChURATA-MASCA, M. G. C. Comportamento de cultivares de cenoura nacionais e importadas nas condições de Pradópolis, SP. In: CONGRESSO BRASILEIRO DE OLERICULTURA, 24., Jaboticabal. 1984. Sociedade de Olericultura do Brasil,. p.29. Resumos.

DELLA VECCHIA, P. T. \& PESSOA, H. B. S. V. Estimativas de herdabilidade para produção comercial de raízes e florescimento prematuro em duas populações de cenoura. In: CONGRESSO BRASILEIRO DE OLERICULTURA, 24., Jaboticabal, 1984. Sociedade de Olericultura do Brasil, p.97. Resumos.

DELLA VECCHIA, P. T.; REIFSCHNEIDER, F.J.B. Estimativa de herdabilidade da resistências Alternaria dauci em cenoura. In: CONGRESSO BRASILEIRO DE OLERICULTURA, 23., Rio de Janeiro, 1983. Sociedade de Olericultura do Brasil. p.141. Resumos 
DOWKER, B. D.; FENNEL, J. F. M.; JACKSON, J. C. Variation studies in carrot as an aid to breeding. Il. Effect of sites, years and densities on some quality characters. Journal Horticultural Science, v.49, p.311-321, 1974 .

FALCONER, D.S. Introducão à genética quantitativa. Viçosa: UFV, Imprensa. Universitária., 1987. 279 P.

FAORO, I. D.; BECKER, W. F.; BUSATO, M. V. Comportamento de cultivares de cenoura na semeadura de setembro a outubro em Caçador, SC. Horticultura Brasileira, v.3, n1, P.68, maio, 1985. Resumo.

FEDERER, W. T. Augmented (or hoonuiaku) designs. Hawaiian Planters Record. v.55, p.191-208, 1956.

FEDERER, W. T. Augmented designs with one way elimination of heterogeneity. Biometrics, v.17, n.3, p.447 - 473, Sep. 1961 a.

FEDERER, W. T. Augmented designs with two three and higher was elimination of heterogeneity (abstract). Biometrics, v.17,n.3, p 166, Sep, $1961 \mathrm{~b}$.

FHER, W. R. Breeding methods for cultivar development. In: WILCOX, J. R., (Ed.) Soybeans; improvement,productions and uses. 2.ed. Madison ASA/CSSA/SSSA, 1987. p.249-293.

FERREIRA, D. F. Uma introdução ao sistema SAS. DEX/UFLA. 1996. 69p. 
HAMBLIN, J.; ZIMMERMAN, M. J. de O. Breeding common bean for yield mixtures. Plant Breeding Reviews, v.4, p.245-272, 1986.

KORLA, B.N.; SINGH, A.K.; RATTAN, R.S. A research note on variability studies in carrot. Punjab Horticultural Journal, v.20, p.215-217, 1980.

LIN, C. S.; POUCHINSKY, G. A modified augmented design for an early stage of plant selection involving a large number of test lines without replication. Biometrics, v.39, p.553-561, 1983.

MAZURKIEWCZ, Z. Analysis of heritability and genotipic variability of morpbological features of the carrot (Daucus carota L.) variety Perfeckja. Bulletin Warziniczy, v.14, p.125-137, 1973.

MCCOLLUM, G.D. Greening of carrot roots (Daucus carota L.): Estimates of heritability and correlation. Euphytica, v.20, p. 549$560,1971$.

MOMENTÉ, V. G. Comparação entre diferentes tipos de famílias clonais para o melhoramento genético da batata /Solanun tuberosum L.) Lavras, 1994. 83p. Dissertação (M.S.) - Escola Superior de Agricultura de Lavras.

NOGUEIRA, M. C. S. Análise conjunta para experimentos em blocos casualizados completos aumentados. Piracicaba, 1976. Dissertação (M.S.) - Escola Superior de Agricultura 'Luiz de Queiroz", Universidade de São Paulo. 
NOGUEIRA, M. C. S.; PIMENTEL GOMES, F. Análise conjunta para experimentos em blocos casualizados completos aumentados. Anais da Escola Superior de Agricultura Luiz de Queiroz, v.35, p.185-224, 1978 a.

NOGUEIRA, M. C. S.; PIMENTEL GOMES, F. Delineamento em blocos casualizados completos aumentados. Anais da Escola Superior de Agricultura Luiz de Queiroz, v.35, p.225-241, 1978b.

PEARCE, S. C. The agricultural field experiment. A statistical examination of theory and practice. New York, John Wiley \& Sons, 1983. 335p.

PESSOA, H. B. S. V.; CORDEIRO, C. M. T. Avaliação de cultivares de cenoura (Daucus carota L.) em semeadura de outono no Distrito Federal. Horticultura Brasileira, v.4, n.1, p67, maio, 1986. Resumo.

PIMENTEL GOMES, F. Curso de estatística experimental. 13.ed. Piracicaba: Nobel, 1990. 468p.

PINTO, C. A. B. P. Melhoramento de hortaliças. Piracicaba: ESALQ, 1977. 319 p. (Apostila)

REIFSCHNEIDER, F. J. B. Queima das folhas de cenoura, um complexo patológico. Fitopatologia Brasileira, v.5, n.3, p.445-446, 1980. Resumo. 
REIFSCHNEIDER, F.J.B. Levantamento e flutuação da ocorrência de Alternaria dauci, Cercospora carotae e Xanthomonas campestris pv. Carotae no Distrito Federal. Fitopatologia Brasileira, v.8, n.3, p.607, 1983. Resumo.

ROBINSON, H. F.; COMSTOCK, R. E.; HARVEY, P. H. Genotypic correlations in corn and their implications in selection. Agronomy Journal, v.43, p.282-284, 1951.

SAS Institute Inc. SAS user's guide: statistics. 5 ed. Cary, 1985. 956p.

SCHAALJE, G. B.; LYNCH, D. R.; LOZUB, G. C. Field evaluation of a modified augmented design for early estage selection involving a large number of test lines without replication. Potato Research, 30: $35-45,1987$.

SCOTT, R. A.; MILLIKEN, G. A. A SAS for analyzing augmented randomized complete-block designs. Crop Science, v.33, p.865$867,1993$.

SILVA, E. A. Análise de covariância em delineamentos de blocos completos aumentados (blocos de Federer). Piracicaba, 1987. 106p. Dissertação (M.S.) - Escola Superior de Agricultura "Luiz de Queiroz", Universidade de São Paulo.

SIQUEIRA, W.J. Seleção intrapopulacional em cenoura (Daucus carota L.) baseada em progênies de meios irmãos. Campinas, 1989. 164 P. Dissertação (M.S.) - Universidade Estadual de Campinas 
SOUZA, E. A. de. Alternativas experimentais na avaliação de progênies em programas de melhoramento genético vegetal. Piracicaba. 1997. 122p. Tese (Doutorado) - Escola Superior de Agricultura "Luiz de Queiroz", Universidade de São Paulo.

SteEL, R. G. D.; TORRIE, J. H. Principles and prodecures of statistics. 2.ed. New York: McGraw-Hill Book Company, 1980. 633p.

VENCOVSKY, R. Herança quantitativa. In: PATTERNIANI, E., (Ed.) Melhoramento e produção de milho. Piracicaba: Fundação Cargill, 1978. p.135-214.

VIEIRA, J. V.; IKUTA, H.; DELLA VECCHIA, P. T. Brasília e Kuronan: novas cultivares de cenoura para o verão. In: CONGRESSO BRASILEIRO DE OLERICULTURA, v.23, p.140, Rio de Janeiro, 1983. Resumo.

VIEIRA, J.V. Herdabilidade, correlações e índice de seleção em populações de cenoura (Daucus carota L.). Viçosa, 1988. 86p. Tese (Doutorado) - Universidade Federal de Viçosa.

VIEIRA, J.V.; CASALI, V.W.D. Melhoramento da cenoura para verão. Informe Agopecuário, v.10, p.17-18, 1984.

VIGGIANO, J. Produção de sementes de cenoura. In: CASTELLANE, P. D.; NICOLOSI, W. M.; HASEGAWA, M. Produção de sementes de hortaliças. Jaboticabal: FCAV/FUNEP, 1990. $261 \mathrm{p}$.

YATES, F. A new method of arranging variety trials involving a large number of varieties. Journal of Agricultural Science, v.26, p.424$455,1936$. 
APÊNDICES 
Tabela 19. Médias de produção total de raízes das progênies e testemunhas nos três delineamentos (DBC, BA1 e BA2)

\begin{tabular}{|c|c|c|c|c|c|c|c|c|c|c|c|}
\hline \multicolumn{2}{|c|}{ Prog. DBC } & $\mathrm{BAl}$ & BA2 & Prog. & $\mathrm{DBC}$ & $\mathrm{BAl}$ & BA2 & Prog. & DBC & $\mathrm{BAl}$ & $B A 2$ \\
\hline 1 & 5575 & 8607 & 3770 & 41 & 4668 & 4722 & 4333 & 81 & 5315 & 7709 & 3367 \\
\hline 2 & 5570 & 9567 & 2800 & 42 & 3750 & 5087 & 2133 & 82 & 4340 & 6459 & 2667 \\
\hline 3 & 5198 & 9072 & 2550 & 43 & 5988 & 6812 & 4883 & 83 & 4430 & 6439 & 2867 \\
\hline 4 & 7087 & 10617 & 4783 & 44 & 6180 & 7247 & 4833 & 84 & 5595 & 7719 & 3917 \\
\hline 5 & 4135 & 6527 & 2970 & 45 & 6060 & 7107 & 4733 & 85 & 5963 & 8354 & 4017 \\
\hline 6 & 5325 & 8127 & 3750 & 46 & 6558 & 8062 & 4773 & 86 & 5311 & 7739 & 3329 \\
\hline 7 & 6508 & 10942 & 3300 & 47 & 6255 & 6697 & 5533 & 87 & 5069 & 7679 & 2905 \\
\hline 8 & 6003 & 10632 & 2600 & 48 & 6445 & 6927 & 5683 & 88 & 4658 & 6794 & 2967 \\
\hline 9 & 4023 & 7802 & 1470 & 49 & 4835 & 5857 & 3533 & 89 & 4080 & 5339 & 3267 \\
\hline 10 & 7400 & 10777 & 5250 & 50 & 7505 & 8597 & 6133 & 90 & 6885 & 8149 & 6067 \\
\hline 11 & 5930 & 10137 & 2950 & 51 & 5205 & 6947 & 3183 & $T 1$ & 5048 & 5925 & 4170 \\
\hline 12 & 4378 & 7152 & 2830 & 52 & 4015 & 5617 & 2133 & $\mathrm{~T} 2$ & 4993 & 6476 & 3510 \\
\hline 13 & 4983 & 7092 & 4100 & 53 & 6700 & 8087 & 5033 & T3 & 6115 & 7210 & 5020 \\
\hline 14 & 6655 & 10187 & 4350 & 54 & 6975 & 7937 & 5733 & & & & \\
\hline 15 & 3955 & 6757 & 2380 & 55 & 7800 & 8067 & 7333 & & & & \\
\hline 16 & 4668 & 6312 & 4250 & 56 & 7725 & 8817 & 6433 & & & & \\
\hline 17 & 7285 & 9947 & 5850 & 57 & 7250 & 8167 & 6133 & & & & \\
\hline 18 & 4518 & 8162 & 2100 & 58 & 6085 & 7437 & 4533 & & & & \\
\hline 19 & 5035 & 5620 & 3257 & 59 & 6118 & 8152 & 3883 & & & & \\
\hline 20 & 5218 & 6655 & 2587 & 60 & 5533 & 7182 & 3683 & & & & \\
\hline 21 & 4090 & 4920 & 2067 & 61 & 5775 & 5817 & 5533 & & & & \\
\hline 22 & 4883 & 5805 & 2767 & 62 & 5670 & 6657 & 4483 & & & & \\
\hline 23 & 4545 & 4930 & 2967 & 63 & 6105 & 6777 & 5233 & & & & \\
\hline 24 & 4678 & 4995 & 3167 & 64 & 5875 & 7817 & 3733 & & & & \\
\hline 25 & 6905 & 6210 & 6407 & 65 & 6115 & 8107 & 3923 & & & & \\
\hline 26 & 5813 & 7965 & 2467 & 66 & 6525 & 8777 & 4073 & & & & \\
\hline 27 & 5925 & 5640 & 5017 & 67 & 6068 & 8842 & 3093 & & & & \\
\hline 28 & 5830 & 7850 & 2617 & 68 & 6088 & 7072 & 4903 & & & & \\
\hline 29 & 6313 & 7565 & 3867 & 69 & 4663 & 6192 & 2933 & & & & \\
\hline 30 & 5805 & 7250 & 3167 & 70 & 4510 & 6337 & 2483 & & & & \\
\hline 31 & 6705 & 8200 & 4017 & 71 & 4848 & 6912 & 2583 & & & & \\
\hline 32 & 9290 & 11880 & 5507 & 72 & 4323 & 6512 & 1933 & & & & \\
\hline 33 & 7208 & 7755 & 5467 & 73 & 4060 & 7599 & 967 & & & & \\
\hline 34 & 7475 & 9580 & 4177 & 74 & 3874 & 7054 & 1140 & & & & \\
\hline 35 & 5725 & 6390 & 3867 & 75 & 4528 & 6084 & 3417 & & & & \\
\hline 36 & 5900 & 6540 & 4067 & 76 & 4875 & 7429 & 2767 & & & & \\
\hline 37 & 6255 & 8817 & 3413 & 77 & 5005 & 7489 & 2967 & & & & \\
\hline 38 & 3990 & 5587 & 2113 & 78 & 4445 & 6519 & 2817 & & & & \\
\hline 39 & 4668 & 6022 & 3033 & 79 & 4825 & 7179 & 2917 & & & & \\
\hline 40 & 3790 & 4377 & 2923 & 80 & 5065 & 6709 & 3867 & & & & \\
\hline
\end{tabular}


Tabela 20. Médias de porcentagem de florescimento prematuro das progênies e testemunhas nos três delineamentos (DBC, BAI e BA2).

\begin{tabular}{|c|c|c|c|c|c|c|c|c|c|c|c|}
\hline \multicolumn{2}{|c|}{ Prog. DBC } & $\mathrm{BAl}$ & $\mathrm{BA} 2$ & Prog. & $\mathrm{DBC}$ & $\mathrm{BAI}$ & $\mathrm{BA2}$ & Prog. & $\mathrm{DBC}$ & $\mathrm{BAl}$ & $\mathrm{BA2}$ \\
\hline$T$ & 41,90 & 42,40 & 48,92 & 41 & 14,56 & 43,61 & 15,23 & 81 & 25,52 & 24,81 & 30,15 \\
\hline 2 & 59,93 & 60,56 & 66,82 & 42 & 23,49 & 12,95 & 24,76 & 82 & 41,42 & 38,09 & 48,67 \\
\hline 3 & 33,18 & 35,99 & 37,89 & 43 & 63,39 & 52,23 & 65,28 & 83 & 17,16 & 15,62 & 22,62 \\
\hline 4 & 15,55 & 23,21 & 15,40 & 44 & 51,60 & 40,57 & 53,36 & 84 & 36,08 & 35,06 & 41,02 \\
\hline 5 & 16,45 & 15,90 & 24,52 & 45 & 39,88 & 36,01 & 34,48 & 85 & 29,56 & 27,44 & 35,59 \\
\hline 6 & 21,11 & 22,23 & 27,51 & 46 & 69,42 & 60,57 & 69,00 & 86 & 26,35 & 18,97 & 37,65 \\
\hline 7 & 15,59 & 16,09 & 22,61 & 47 & 31,93 & 25,48 & 29,10 & 87 & 17,60 & 14,89 & 24,23 \\
\hline 8 & 53,41 & 54,04 & 60,30 & 48 & 0,00 & 0,00 & 0,00 & 88 & 26,73 & 21,73 & 35,64 \\
\hline 9 & 41.51 & 43,80 & 46,74 & 49 & 47,92 & 36,76 & 49,81 & 89 & 18,57 & 15,37 & 25,69 \\
\hline 10 & 23,22 & 26,99 & 26.96 & 50 & 32,73 & 24,20 & 31,99 & 90 & 57,56 & 66,02 & 53,02 \\
\hline 11 & 12,15 & 21,56 & 10,26 & 51 & 24,32 & 14,95 & 24,42 & $T 1$ & 59,98 & 57,34 & 62,18 \\
\hline 12 & 6.11 & 5,56 & 14,18 & 52 & 22,19 & 13,34 & 21,77 & 12 & 73.11 & 64.91 & 81,30 \\
\hline 13 & 9,20 & 10,32 & 15,60 & 53 & 16,68 & 3,90 & 20,18 & Т3 & 0,00 & 0,00 & 0,00 \\
\hline 14 & 24,93 & 25,56 & 31,82 & 54 & 33,01 & 22,47 & 34,28 & & & & \\
\hline 15 & 67,37 & 69,66 & 72,60 & 55 & 32,94 & 35,75 & 32,85 & & & & \\
\hline 16 & 50,22 & 60,11 & 47,85 & 56 & 30,06 & 27,42 & 35,42 & & & & \\
\hline 17 & 44,21 & 43,66 & 52,28 & 57 & 16,04 & 13,53 & 21,27 & & & & \\
\hline 18 & 66,51 & 67,63 & 72,91 & 58 & 28,27 & 27.42 & 31,84 & & & & \\
\hline 19 & 39,90 & 38,34 & 36,58 & 59 & 14,04 & 16.71 & 14,09 & & & & \\
\hline 20 & 27,52 & 19,48 & 30,69 & 60 & 72,27 & 70,84 & 76,41 & & & & \\
\hline 21 & 61,06 & 52,40 & 64,85 & 61 & 18,61 & 14,92 & 25,02 & & & & \\
\hline 22 & 37,70 & 36,40 & 34,13 & 62 & 25,37 & 32,85 & 20,61 & & & & \\
\hline 23 & 0,00 & 0,00 & 0,00 & 63 & 62,75 & 60,11 & 68,11 & & & & \\
\hline 24 & 62.01 & 55,66 & 63.49 & 64 & 33,34 & 31,83 & 37,57 & & & & \\
\hline 25 & 32,20 & 22,49 & 37,04 & 65 & 25,33 & 25,00 & 28,38 & & & & \\
\hline 26 & 36,44 & 28,40 & 39,61 & 66 & 29,98 & 32,05 & 30,62 & & & & \\
\hline 27 & 32,88 & 28,22 & 32,67 & 67 & 29,64 & 25,95 & 36,05 & & & & \\
\hline 28 & 62,82 & 54,29 & 66,48 & 68 & 18,23 & 16,21 & 22,97 & & & & \\
\hline 29 & 23,58 & 17,23 & 25,06 & 69 & 20,69 & 18,05 & 26,05 & & & & \\
\hline 30 & 12,75 & 8,90 & 11,73 & 70 & 56,93 & 54,42 & 62,16 & & & & \\
\hline 31 & 66,11 & 56,40 & 70,95 & 71 & 28,61 & 26.10 & 33,84 & & & & \\
\hline 32 & 52,68 & 61,40 & 39,08 & 72 & 36,08 & 35,75 & 39,13 & & & & \\
\hline 33 & 75,65 & 66,99 & 79,44 & 73 & 38,25 & 33,87 & 46,55 & & & & \\
\hline 34 & 65,80 & 57,27 & 69,46 & 74 & 25,63 & 22,42 & 32,76 & & & & \\
\hline 35 & 52,25 & 50,57 & 49,05 & 75 & 0,00 & 1,73 & 2,19 & & & & \\
\hline 36 & 13,46 & 7.11 & 14,94 & 76 & 34,93 & 31,73 & 42,05 & & & & \\
\hline 37 & 16,17 & 5,01 & 18,06 & 77 & 29,08 & 27,54 & 34,54 & & & & \\
\hline 38 & 42,68 & 34,93 & 41,15 & 78 & 31,32 & 30,30 & 36,26 & & & & \\
\hline 39 & 15,27 & 5,90 & 15,37 & 79 & 10,83 & 8,71 & 16,86 & & & & \\
\hline 40 & 17.98 & 11.85 & 14,83 & 80 & 9,44 & 5.06 & 17,74 & & & & \\
\hline
\end{tabular}


Tabela 21. Médias de peso médio de raizes comerciais das progênies e testemunhas nos três delineamentos (DBC, BA1 e BA2).

\begin{tabular}{|c|c|c|c|c|c|c|c|c|c|c|c|}
\hline \multicolumn{2}{|c|}{ Prog. DBC } & \multirow{2}{*}{$\frac{\mathrm{BAl}}{124,39}$} & \multirow{2}{*}{$\frac{B A 2}{66,76}$} & \multirow{2}{*}{$\begin{array}{r}\text { Prog. } \\
41\end{array}$} & \multirow{2}{*}{$\frac{\mathrm{DBC}}{75,93}$} & \multirow{2}{*}{$\frac{B A 1}{81,61}$} & \multirow{2}{*}{$\frac{B A 2}{76,38}$} & \multirow{2}{*}{$\frac{\text { Prog. }}{81}$} & \multirow{2}{*}{$\frac{\mathrm{DBC}}{90,16}$} & \multirow{2}{*}{$\frac{B A 1}{117,30}$} & \multirow{2}{*}{$\frac{\mathrm{BA} 2}{56,67}$} \\
\hline 1 & 86.51 & & & & & & & & & & \\
\hline 2 & 87,30 & 131,52 & 61,22 & 42 & 61,19 & 84,46 & 44,05 & 82 & 71,05 & 96,22 & 39,53 \\
\hline 3 & 93,38 & 147,07 & 57,82 & 43 & 106,00 & 125,75 & 92,38 & 83 & 80,10 & 115,51 & 38,34 \\
\hline 4 & 92,22 & 123,74 & 78,84 & 44 & 118,31 & 155,75 & 87,00 & 84 & 106,86 & 136,16 & 71,22 \\
\hline 5 & 70,12 & 100,87 & 57,51 & 45 & 78,78 & 79,31 & 84,38 & 85 & 98,76 & 127,31 & 63,87 \\
\hline 6 & 99,04 & 141,96 & 74,26 & 46 & 112,23 & 142,50 & 88,09 & 86 & 98,42 & 138,57 & 51,93 \\
\hline 7 & 84,45 & 114,85 & 72,18 & 47 & 102,73 & 109,20 & 102,38 & 87 & 90,56 & 121,11 & 53,67 \\
\hline 8 & 96,80 & 163,92 & 47,82 & 48 & 118,72 & 130,07 & 113,49 & 88 & 80,37 & 109,72 & 44,67 \\
\hline 9 & 74,89 & 124,55 & 43,37 & 49 & 101,25 & 138,75 & 69,88 & 89 & 79,29 & 85,56 & 66,67 \\
\hline 10 & 117,26 & 162,15 & 90,51 & 50 & 117,46 & 134,11 & 106,93 & 90 & 91,25 & 63,66 & 112,50 \\
\hline 11 & 95,03 & 137,13 & 71,07 & 51 & 91,03 & 116,61 & 71.58 & $T 1$ & 92,75 & 99,47 & 86,05 \\
\hline 12 & 75,95 & 109,77 & 60,27 & 52 & 80,63 & 97,50 & 69,88 & $\mathrm{~T} 2$ & 77,35 & 79,90 & 74,80 \\
\hline 13 & 78,21 & 109.96 & 64,60 & 53 & 103,24 & 130,22 & 82,38 & T3 & 114,56 & 111,88 & 17,24 \\
\hline 14 & 109,98 & 156,27 & 81,83 & 54 & 132,50 & 193,75 & 77,38 & & & & \\
\hline 15 & 76,43 & 116,48 & 54,51 & 55 & 103,33 & 120,85 & 84,60 & & & & \\
\hline 16 & 83,00 & 100,63 & 83,51 & 56 & 104,00 & 145,52 & 61,27 & & & & \\
\hline 17 & 105,53 & 133,68 & 95,51 & 57 & 106,25 & 140,02 & 71,27 & & & & \\
\hline 18 & 107,94 & 136,84 & 97,18 & 58 & 89,75 & 95,02 & 83,27 & & & & \\
\hline 19 & 94,36 & 107,03 & 64,97 & 59 & 102,18 & 128,02 & 75,12 & & & & \\
\hline 20 & 93,96 & 118,28 & 52,92 & 60 & 88,95 & 115,02 & 61,67 & & & & \\
\hline 21 & 73,04 & 84,76 & 44,60 & 61 & 100,21 & 102,14 & 97,06 & & & & \\
\hline 22 & 84,45 & 102,44 & 49,73 & 62 & 90,07 & 100,65 & 78,27 & & & & \\
\hline 23 & 75,19 & 85,78 & 47,87 & 63 & 94,01 & 111,09 & 75,71 & & & & \\
\hline 24 & 84,43 & 86,38 & 65,75 & 64 & 79,55 & 102,52 & 55,36 & & & & \\
\hline 25 & 117,09 & 119.11 & 98,34 & 65 & 101,00 & 129,52 & 71,27 & & & & \\
\hline 26 & 96,14 & 127.68 & 47,87 & 66 & 115,59 & 152,23 & 77,74 & & & & \\
\hline 27 & 96,25 & 91,61 & 84,17 & 67 & 99,14 & 139,34 & 57,72 & & & & \\
\hline 28 & 101,61 & 136,33 & 50.17 & 68 & 104,40 & 126,85 & 80,74 & & & & \\
\hline 29 & 98,95 & 125,58 & 55,60 & 69 & 72,27 & 89,06 & 54,27 & & & & \\
\hline 30 & 90,84 & 135,11 & 29,85 & 70 & 71,43 & 100,38 & 41,27 & & & & \\
\hline 31 & 113,75 & 139,11 & 71,67 & 71 & 83,32 & 121,43 & 44,00 & & & & \\
\hline 32 & 148,19 & 186,25 & 93,40 & 72 & 78,20 & 122,52 & 32,67 & & & & \\
\hline 33 & 102.50 & 104,11 & 84,17 & 73 & 71,56 & 115,56 & 21,22 & & & & \\
\hline 34 & 68,68 & 50,36 & 70,28 & 74 & 64,65 & 103,66 & 19,30 & & & & \\
\hline 35 & 94.57 & 106.17 & 66,25 & 75 & 56,78 & 58,24 & 48,98 & & & & \\
\hline 36 & 96,37 & 99.11 & 76,90 & 76 & 86,69 & 117,58 & 49.45 & & & & \\
\hline 37 & 117,91 & 177,75 & 64,20 & 77 & 78,25 & 99,37 & 50.79 & & & & \\
\hline 38 & 75,00 & 108,75 & 47,38 & 78 & 72,00 & 96,99 & 40,67 & & & & \\
\hline 39 & 66,27 & 120,42 & 18,24 & 79 & 60,42 & 71,99 & 42,50 & & & & \\
\hline 40 & 66.66 & 92,68 & 46,76 & 80 & 86,20 & 98,24 & 67,82 & & & & \\
\hline
\end{tabular}


Tabela 22. Médias de porcentagem de raízes comerciais das progênies e testemunhas nos três delineamentos (DBC, BAI e BA2).

\begin{tabular}{|c|c|c|c|c|c|c|c|c|c|c|c|}
\hline & $\mathrm{BAl}$ & $\mathrm{BA} 2$ & Prog. & $\mathrm{DBC}$ & $\mathrm{BAl}$ & $B A 2$ & Prog. & $\mathrm{DBC}$ & $\mathrm{BAl}$ & BA2 \\
\hline \multicolumn{2}{|c|}{$\frac{\text { Prog. DBC }}{1}$} & 87,04 & 58,68 & 41 & 52,78 & 59,23 & 58,32 & 81 & 73,53 & 74,71 & 63,46 \\
\hline 2 & 83,89 & 87,57 & 74,92 & 42 & 68,63 & 75,90 & 73,35 & 82 & 52,88 & 51,75 & 45,13 \\
\hline 3 & 63,21 & 75,83 & 45,29 & 43 & 48,11 & 50,90 & 57,31 & 83 & 80,36 & 67,66 & 84,17 \\
\hline 4 & 59,81 & 50,51 & 63,81 & 44 & 60,42 & 75,90 & 56,93 & 84 & 73,03 & 65,39 & 71,79 \\
\hline 5 & 52,93 & 56,19 & 97,14 & 45 & 51,47 & 56,60 & 58,32 & 85 & 82,17 & 81,23 & 74,22 \\
\hline 6 & 77,41 & 60,07 & 89,45 & 46 & 68,34 & 75,90 & 72,76 & 86 & 62,45 & 58,18 & 57,84 \\
\hline 7 & 80,71 & 92,31 & 63,81 & 47 & 53,95 & 67,12 & 52,76 & 87 & 64,74 & 82,13 & 38,46 \\
\hline 8 & 87,60 & 91,51 & 78,39 & 48 & 70,26 & 74,75 & 77.76 & 88 & 72,15 & 86,95 & 48,46 \\
\hline 9 & 60,82 & 74,04 & 42,30 & 49 & 53,57 & 66,37 & 52,76 & 89 & 52,28 & 72,21 & 23,46 \\
\hline 10 & 62.50 & 72,57 & 47,14 & 50 & 88,26 & 94,08 & 94,43 & 90 & 72,80 & 67,66 & 69,05 \\
\hline 11 & 77,50 & 77,57 & 72,14 & 51 & 47,49 & 46,07 & 60,90 & II & 61,03 & 62,39 & 59.66 \\
\hline 12 & 78,84 & 71,25 & 81,14 & 52 & 48,72 & 75,90 & 33,53 & T2 & 42,19 & 26,61 & 57.77 \\
\hline 13 & 78,03 & 69,00 & 81.76 & 53 & 45,00 & 65,90 & 36,09 & T3 & 67,65 & 62,55 & 72,74 \\
\hline 14 & 74,61 & 60,43 & 83,50 & 54 & 35,12 & 12,80 & 69,43 & & & & \\
\hline 15 & 43,69 & 30,90 & 51,19 & 55 & 46,67 & 40,87 & 56,12 & & & & \\
\hline 16 & 56,19 & 54,39 & 52,70 & 56 & 36,00 & 32,54 & 43,12 & & & & \\
\hline 17 & 82,74 & 88,05 & 72,14 & 57 & 33,33 & 51,98 & 18,34 & & & & \\
\hline 18 & 50,94 & 63,09 & 33,50 & 58 & 41,25 & 27,54 & 58,62 & & & & \\
\hline 19 & 77,78 & 70,43 & 83,64 & 59 & 59,79 & 78,97 & 44,27 & & & & \\
\hline 20 & 75,79 & 85,32 & 64,77 & 60 & 64,48 & 70,70 & 61,91 & & & & \\
\hline 21 & 85,66 & 85,01 & 84,82 & 61 & 70,50 & 72,54 & 72,12 & & & & \\
\hline 22 & 88,91 & 89,01 & 87,33 & 62 & 71,82 & 77,11 & 70,19 & & & & \\
\hline 23 & 71,59 & 61,19 & 80,51 & 63 & 61,54 & 61,39 & 65,35 & & & & \\
\hline 24 & 74,67 & 74,49 & 73,37 & 64 & 46,62 & 19,30 & 77,60 & & & & \\
\hline 25 & 61,74 & 36,49 & 85,51 & 65 & 59,75 & 55,93 & 67,23 & & & & \\
\hline 26 & 59,40 & 49,01 & 68,30 & 66 & 65,48 & 70,50 & 64,12 & & & & \\
\hline 27 & 80,12 & 65,74 & 93,01 & 67 & 70,16 & 72,25 & 71,73 & & & & \\
\hline 28 & 81,86 & 87,75 & 74.48 & 68 & 73,36 & 59.26 & 91,12 & & & & \\
\hline 29 & 76,59 & 63,84 & 87,86 & 69 & 52,58 & 48,17 & 60,64 & & & & \\
\hline 30 & 74,28 & 55,51 & 91.56 & 70 & 66,10 & 63,54 & 72,31 & & & & \\
\hline 31 & 77.78 & 59,68 & 94,40 & 71 & 76,10 & 68,07 & 87,79 & & & & \\
\hline 32 & 81,43 & 63,01 & 98,37 & 72 & 61,52 & 44,58 & 82,12 & & & & \\
\hline 33 & 53,43 & 16,54 & 88,84 & 73 & 38,75 & 42,66 & 25,96 & & & & \\
\hline 34 & 62,39 & 27,79 & 95,51 & 74 & 50,22 & 44,38 & 47,18 & & & & \\
\hline 35 & 78,27 & 63,84 & 91,22 & 75 & 62,39 & 30,76 & 85,13 & & & & \\
\hline 36 & 75,00 & 64,44 & 84,08 & 76 & 65,84 & 49,33 & 73,46 & & & & \\
\hline 37 & 42,07 & 4,79 & 81,33 & 77 & 69,29 & 60,40 & 69.29 & & & & \\
\hline 38 & 62,56 & 81,02 & 56,09 & 78 & 78,80 & 68,85 & 79,86 & & & & \\
\hline 39 & 60,65 & 45,23 & 88,05 & 79 & 75,20 & 76,38 & 65,13 & & & & \\
\hline 40 & 84,38 & 81.02 & 99.73 & 80 & 78,24 & 72,66 & 74,93 & & & & \\
\hline
\end{tabular}


Tabela 23. Médias de peso médio de raízes cilíndricas comerciais das progênies e testemunhas nos três delineamentos (DBC, BAI e BA2).

\begin{tabular}{|c|c|c|c|c|c|c|c|c|c|c|c|}
\hline \multicolumn{2}{|c|}{ Prog. DBC } & \multirow{2}{*}{$\frac{B A 1}{112,47}$} & \multirow{2}{*}{$\frac{B A 2}{0,00}$} & \multirow{2}{*}{$\frac{\text { Prog. }}{41}$} & \multirow{2}{*}{$\frac{\mathrm{DBC}}{86,19}$} & \multirow{2}{*}{$\frac{B A 1}{75,85}$} & \multirow{2}{*}{$\frac{B A 2}{96,65}$} & \multirow{2}{*}{$\frac{\text { Prog. }}{81}$} & \multirow{2}{*}{$\frac{\mathrm{DBC}}{85.72}$} & \multirow{2}{*}{$\frac{B A 1}{116,80}$} & \multirow{2}{*}{$\frac{\mathrm{BA2}}{48,81}$} \\
\hline 1 & 54,55 & & & & & & & & & & \\
\hline 2 & 64,77 & 106,24 & 24,15 & 42 & 53,54 & 73,47 & 33,73 & 82 & 0,00 & 0,00 & 0,00 \\
\hline 3 & 61,54 & 126,46 & 0,00 & 43 & 113,10 & 143,00 & 83,31 & 83 & 77.08 & 108,10 & 40,24 \\
\hline 4 & 72,50 & 148,38 & 0,00 & 44 & 102,50 & 125,14 & 79,98 & 84 & 99,59 & 154,54 & 38,81 \\
\hline 5 & 64,12 & 91,62 & 37,48 & 45 & 50,00 & 70,14 & 29,98 & 85 & 78,75 & 85,37 & 66,31 \\
\hline 6 & 99,59 & 115,88 & 84,15 & 46 & 105,00 & 100,14 & 109,98 & 86 & 59,50 & 79,37 & 33,81 \\
\hline 7 & 66,67 & 136.71 & 0,00 & 47 & 62,50 & 125,14 & 0,00 & 87 & 80,63 & 111,62 & 43,81 \\
\hline 8 & 82,00 & 167,38 & 0,00 & 48 & 95,37 & 112,87 & 77.98 & 88 & 65,00 & 125,37 & 0,00 \\
\hline 9 & 44,00 & 91,38 & 0,00 & 49 & 59,50 & 94,14 & 24,98 & 89 & 39.67 & 74,70 & 0,00 \\
\hline 10 & 105,00 & 103,38 & 107,48 & 50 & 109,48 & 119.09 & 99,98 & 90 & 58,57 & 112,51 & 0,00 \\
\hline 11 & 71,25 & 85,88 & 57,48 & 51 & 66,14 & 55,14 & 77.25 & $T 1$ & 92,33 & 113,00 & 71,66 \\
\hline 12 & 65,00 & 60,05 & 70,81 & 52 & 42,15 & 84,43 & 0,00 & $T 2$ & 63,30 & 71,50 & 55,10 \\
\hline 13 & 72,34 & 81,38 & 64,15 & 53 & 55,00 & 110,14 & 0,00 & T3 & 82,48 & 93.26 & 71,73 \\
\hline 14 & 110,36 & 138,38 & 83,19 & 54 & 40,00 & 80,14 & 0,00 & & & & \\
\hline 15 & 74.17 & 91.71 & 57,48 & 55 & 68,34 & 138,80 & 3,36 & & & & \\
\hline 16 & 66,67 & 76.71 & 57,48 & 56 & 75,00 & 152,13 & 3,36 & & & & \\
\hline 17 & 74,59 & 152,55 & 0,00 & 57 & 70,00 & 142,13 & 3,36 & & & & \\
\hline 18 & 97.28 & 107,93 & 87.48 & 58 & 55,00 & 112.13 & 3,36 & & & & \\
\hline 19 & 83,00 & 114,97 & 50,37 & 59 & 92,00 & 136,13 & 53,36 & & & & \\
\hline 20 & 91,84 & 122,65 & 60,37 & 60 & 73,00 & 107.13 & 44,36 & & & & \\
\hline 21 & 76,55 & 108,06 & 44,37 & 61 & 88,13 & 112.13 & 69.61 & & & & \\
\hline 22 & 56,11 & 77,86 & 33,70 & 62 & 72,50 & 82,13 & 68,36 & & & & \\
\hline 23 & 82,50 & 98,97 & 65,37 & 63 & 100,13 & 125,46 & 80,28 & & & & \\
\hline 24 & 48,57 & 96,11 & 0,37 & 64 & 71,00 & 112,13 & 35,36 & & & & \\
\hline 25 & 131,88 & 142,72 & 120,37 & 65 & 38,34 & 2,13 & 80,03 & & & & \\
\hline 26 & 69,38 & 107,72 & 30,37 & 66 & 63,50 & 127,13 & 5,36 & & & & \\
\hline 27 & 103,34 & 125,64 & 80,37 & 67 & 90,00 & 127.13 & 58,36 & & & & \\
\hline 28 & 70,56 & 140,08 & 0,37 & 68 & 95,89 & 116,13 & 81,14 & & & & \\
\hline 29 & 105,00 & 141,47 & 67,87 & 69 & 72,50 & 97.13 & 53,36 & & & & \\
\hline 30 & 31,00 & $-1,03$ & 62,37 & 70 & 81,67 & 132,13 & 36.69 & & & & \\
\hline 31 & 175,00 & 248,97 & 100,37 & 71 & 68,75 & 107.13 & 35,86 & & & & \\
\hline 32 & 127,50 & 163,97 & 90,37 & 72 & 79,75 & 124,13 & 40,86 & & & & \\
\hline 33 & 57,50 & 113,97 & 0,37 & 73 & 61,25 & 117,87 & 0,00 & & & & \\
\hline 34 & 140,63 & 208,97 & 71,62 & 74 & 85,00 & 115,37 & 48,81 & & & & \\
\hline 35 & 102,86 & 133,26 & 71,80 & 75 & 30,00 & 55,37 & 0,00 & & & & \\
\hline 36 & 82,50 & 98,97 & 65,37 & 76 & 77,78 & 84,26 & 65,48 & & & & \\
\hline 37 & 55,00 & 110,14 & 0,00 & 77 & 70,00 & 135,37 & 0,00 & & & & \\
\hline 38 & 88,85 & 107,83 & 69,98 & 78 & 58,74 & 84,84 & 26,81 & & & & \\
\hline 39 & 80,67 & 110,14 & 51,31 & 79 & 65,79 & 76,95 & 48,81 & & & & \\
\hline 40 & 68,13 & 86,39 & 49,98 & 80 & 83,75 & 75,37 & 86,31 & & & & \\
\hline
\end{tabular}


Tabela 24. Médias de porcentagem de raizes cilindricas comerciais das progênies e testemunhas nos três delineamentos (DBC, BAI e BA2).

\begin{tabular}{|c|c|c|c|c|c|c|c|c|c|c|c|}
\hline \multicolumn{2}{|c|}{ Prog. DBC } & $\mathrm{BAl}$ & $B A 2$ & Prog. & $\mathrm{DBC}$ & $\mathrm{BAI}$ & $\mathrm{BA2}$ & Prog. & $\mathrm{DBC}$ & $\mathrm{BAI}$ & $\mathrm{BA2}$ \\
\hline 1 & 28,95 & 58,31 & 0,00 & 41 & 18,06 & 23,42 & 13,25 & 81 & 25,45 & 31,80 & 14,82 \\
\hline 2 & 25,84 & 35,42 & 16,31 & 42 & 26,05 & 26,99 & 25,67 & 82 & 0,00 & 0,00 & 0,00 \\
\hline 3 & 28,26 & 56,94 & 0,00 & 43 & 28,22 & 27,59 & 29,41 & 83 & 27.78 & 26,46 & 24,82 \\
\hline 4 & 5,88 & 12.18 & 0,00 & 44 & 19,59 & 25,09 & 14,64 & 84 & 24,85 & 32,26 & 13,15 \\
\hline 5 & 39,31 & 59,04 & 19,64 & 45 & 13,45 & 14,21 & 13,25 & 85 & 22,12 & 15,90 & 24,06 \\
\hline 6 & 30,77 & 50,42 & 11,18 & 46 & 15,42 & 19,25 & 12,14 & 86 & 14,87 & 13,14 & 12,32 \\
\hline 7 & 15,79 & 32,00 & 0,00 & 47 & 10,53 & 19,47 & 2,14 & 87 & 25,06 & 38,01 & 7,82 \\
\hline 8 & 15,15 & 30,72 & 0,00 & 48 & 39,80 & 36,35 & 43,81 & 88 & 14,29 & 24,47 & 0,00 \\
\hline 9 & 7,36 & 15,13 & 0,00 & 49 & 20,54 & 26,99 & 14,64 & 89 & 17,05 & 29,99 & 0,00 \\
\hline 10 & 15,18 & 18,28 & 12,14 & 50 & 32,96 & 56,00 & 10,47 & 90 & 12,50 & 20,90 & 0,00 \\
\hline 11 & 26,75 & 16,42 & 37,14 & 51 & 18,06 & 8,95 & 27.72 & 91 & 23,59 & 8,20 & 38,98 \\
\hline 12 & 13,90 & 16,21 & 11,64 & 52 & 19.45 & 37,31 & 2,14 & 92 & 21,22 & 23,12 & 19,32 \\
\hline 13 & 23,45 & 24,23 & 22,72 & 53 & 10,00 & 18,42 & 2,14 & 93 & 50,71 & 26,98 & 74,45 \\
\hline 14 & 35,91 & 40,42 & 31,46 & 54 & 8,93 & 16,28 & 2,14 & & & & \\
\hline 15 & 14,45 & 15,80 & 13,15 & 55 & 8,34 & 17,54 & 0,21 & & & & \\
\hline 16 & 25,38 & 34,51 & 16,31 & 56 & 2,50 & 5,87 & 0,21 & & & & \\
\hline 17 & 28,57 & 57,56 & 0,00 & 57 & 13,89 & 28,65 & 0,21 & & & & \\
\hline 18 & 20,48 & 38,35 & 2,67 & 58 & 2,50 & 5,87 & 0,21 & & & & \\
\hline 19 & 27,07 & 36,65 & 20,07 & 59 & 10,78 & 18,73 & 3,91 & & & & \\
\hline 20 & 45,80 & 77,47 & 16,71 & 60 & 23,69 & 21,92 & 26,53 & & & & \\
\hline 21 & 39,24 & 48,39 & 32,67 & 61 & 36,00 & 40,87 & 32,21 & & & & \\
\hline 22 & 24,82 & 40,39 & 11,83 & 62 & 35,91 & 35,65 & 37,25 & & & & \\
\hline 23 & 26,52 & 40,75 & 14,86 & 63 & 36,54 & 23,95 & 50,21 & & & & \\
\hline 24 & 12,97 & 30,32 & 0,00 & 64 & 12,20 & 6,75 & 18,73 & & & & \\
\hline 25 & 24,06 & 39.17 & 11,52 & 65 & 10,00 & 0,87 & 20,21 & & & & \\
\hline 26 & 20,65 & 36,39 & 7,49 & 66 & 13.71 & 8,28 & 20,21 & & & & \\
\hline 27 & 19,89 & 31,66 & 10.69 & 67 & 15,64 & 12,63 & 19,72 & & & & \\
\hline 28 & 23,69 & 51,76 & 1.81 & 68 & 31,12 & 18,11 & 45,21 & & & & \\
\hline 29 & 31,87 & 21,06 & 45,25 & 69 & 25,61 & 13,37 & 38,92 & & & & \\
\hline 30 & 11,63 & 4,39 & 21,45 & 70 & 15,57 & 24,87 & 7,35 & & & & \\
\hline 31 & 8,89 & 11,06 & 9,30 & 71 & 24,56 & 16,66 & 33,54 & & & & \\
\hline 32 & 19.29 & 14,39 & 26,76 & 72 & 17,26 & 19,39 & 16,21 & & & & \\
\hline 33 & 5,88 & 16,15 & 0,00 & 73 & 7,15 & 10,19 & 0,00 & & & & \\
\hline 34 & 30,87 & 26,13 & 38.19 & 74 & 13,35 & 20,04 & 2,38 & & & & \\
\hline 35 & 27,09 & 33,56 & 23,19 & 75 & 11,91 & 19.71 & 0,00 & & & & \\
\hline 36 & 46,43 & 68,68 & 26.76 & 76 & 21,25 & 25,90 & 12,32 & & & & \\
\hline 37 & 13,89 & 26,20 & 2,14 & 77 & 8,07 & 12,03 & 0,00 & & & & \\
\hline 38 & 18,33 & 31.75 & 5.47 & 78 & 28,44 & 41,14 & 11,45 & & & & \\
\hline 39 & 32,06 & 18,42 & 46,26 & 79 & 27.65 & 40,09 & 10,93 & & & & \\
\hline 40 & 13,29 & 18,93 & 8,20 & 80 & 16,77 & 5,90 & 23,35 & & & & \\
\hline
\end{tabular}

